This PDF is a selection from an out-of-print volume from the National Bureau of Economic Research

Volume Title: Tax Policy and the Economy, volume 13

Volume Author/Editor: James M. Poterba, editor

Volume Publisher: MIT Press

Volume ISBN: 0-262-66150-0

Volume URL: http://www.nber.org/books/pote99-2

Publication Date: January 1999

Chapter Title: Tobacco Taxes and Public Policy to Discourage Smoking

Chapter Author: William N. Evans, Jeanne S. Ringel, Diana Stech

Chapter URL: http://www.nber.org/chapters/c10920

Chapter pages in book: (p. 1 - 56) 


\section{TOBACCO TAXES AND PUBLIC POLICY TO DISCOURAGE SMOKING}

\section{William N. Evans}

University of Maryland

\section{Jeanne S. Ringel}

Louisiana State University

\section{Diana Stech}

University of Maryland

\section{EXECUTIVE SUMMARY}

In this paper, we present evidence of the likely impact of cigarette tax hikes on consumers, governments, and producers. We show that 100 percent of a tax hike is passed onto consumers in the form of higher prices. Using both state and individual-level data, we find a cigarette demand elasticity of -0.30 to -0.50 , with long-term elasticities 1.75 times the short-term values. We demonstrate that cigarette taxes have become much more regressive over time as smoking rates among the highest income groups have fallen sharply. One reason for this drop is the large decline in smoking rates for the most educated. Given their ability to shift tax increases onto consumers, tobacco companies bear little of the burden of a tax. We estimate that for every $\$ 1$ raised in tax revenues, cigarette companies lose only 8 cents in before-tax profits. Using daily stock prices, 
we conduct an event study examining how new information about litigation and settlement of state Medicaid cases against cigarette manufacturers changed the value of the firm. Events that increased the plaintiffs' chances in state Medicaid cases had a statistically significant negative impact on firm value while movements toward settlement greatly increased stock prices. Finally, we consider the external costs of smoking. Although some argue that current tax revenues exceed the external costs of smoking, these estimates typically exclude the costs of maternal smoking. We show that the costs of maternal smoking range from $\$ 0.42-\$ 0.72$ per pack which makes the question of whether these costs should be considered external critical in any cost-benefit analysis.

\section{INTRODUCTION}

On May 23, 1994, the attorney general's office of the state of Mississippi filed a lawsuit against tobacco manufacturers, wholesalers, trade associations, and industry public-relations consultants seeking reimbursement for the costs associated with treating smoking-related illness and disease in state medical programs. At the time, the Mississippi lawsuit generated little attention. The day after the suit was filed, the Wall Street Journal covered the story on page A2, the New York Times covered it on page A12, and the Washington Post contained no mention of the story. In fact, less attention was paid to the potential outcome of the Mississippi lawsuit than to the fact that Governor Kirk Fordice, a Republican, was locked in a legal battle with the Attorney General Michael Moore, a Democrat, over the attorney general's authority to file a suit over the governor's objections.

The lack of attention to the Mississippi case in the spring of 1994 is in stark contrast to the monumental changes that have occurred in the political landscape since then. A total of 40 other states have filed suits similar to the Mississippi one. In response to the mounting legal uncertainty, a tobacco-industry settlement (hereafter referred to as the Settlement) was reached between the states' attorneys general and the tobacco manufacturers requiring the defendants to pay an estimated $\$ 368$ billion to states over a 25 -year period. ${ }^{1}$ The Settlement was expected to raise cigarette prices by about 60 cents per pack after 5 years (Federal Trade Commission, 1997; Congressional Budget Office, 1998). The structure of the Settlement required the federal government to pass legislation limiting liability of cigarette manufacturers, granting the Food and Drug

\footnotetext{
${ }^{1}$ The text of the Settlement can be found at the State Tobacco Information Center Web page, stic.neu.edu.
} 
Administration (FDA) authority to regulate cigarettes, and regulating the practices of cigarette manufacturers who were not parties of the Settlement. These aspects of the Settlement prompted the federal government to become more involved in constructing tobacco legislation. In lieu of the Settlement, President Clinton proposed federal cigarette taxes be raised by $\$ 1.50$ per pack, primarily to decrease the number of young smokers. Then, in more sweeping legislation, Senator McCain (R-AZ) proposed cigarette manufacturers pay an estimated \$564 billion in fines over 25 years. ${ }^{2}$ Further, the McCain bill contained less generous liability protection than what had been agreed to in the Settlement. In the end, neither the Settlement nor the McCain bill was enacted. However, the mere fact that the federal government was considering policies that would raise the price of cigarettes by $\$ 1.50$ per pack is a historic change.

These legal and legislative events have brought attention to economic research concerning the likely impacts of changes in tobacco excise taxes. In contrast to many other proposed policies, the work of economists was prominently featured in debates concerning tobacco legislation. ${ }^{3}$ The discussions about the likely impact of tax increases on prices and demand in general, and teen smoking in particular, have relied heavily on the work of economists. In addition, economic research has been cited in many of the discussions regarding the external costs of smoking, the perceptions of the risks of smoking, and the regressivity of excise taxes.

In this paper, we present evidence of the likely impacts of cigarette excise-tax increases. Much of what we present is generic to any type of tax change; however, some of it is particular to proposals such as the Settlement. The paper has a simple structure in that we discuss how tax hikes impact consumers, governments, and producers. In sections 2 and 3 , we provide some basic background information on the cigarette industry and a short description of recent tobacco control policies. In section 4, we provide a detailed analysis of the likely impact of tax hikes on the demand for cigarettes. We first outline how taxes affect price. We demonstrate that, consistent with other studies, producers pass 100 percent of a tax increase onto consumers in the form of higher prices. We then discuss the likely impact of higher taxes on consumption. In contrast to some other papers, we choose not to review the large number of cigarette demand studies. Instead, we establish some qualities we would

2 The text of the McCain bill, S.1415, can be found in the Thomas Legislative Information page on the Web, http://thomas.loc.gov/home/thomas2.html.

3 We should also point out that a large portion of this work was either distributed as National Bureau of Economic Research (NBER) working papers or published in NBER volumes. 
prefer to see in these estimates and use them as guidelines when we construct demand estimates using aggregate and individual level data. The short-term demand elasticity results we find are consistent across samples, about -0.30 to -0.50 , with half of the demand change brought about by a reduction in the number of smokers. Since many major tobacco control programs would generate non-marginal changes in prices, we also consider the long-term impacts of tax hikes. Our results show long-term elasticities are 1.75 times the short-term values, consistent with other studies. More importantly, our regression-based estimates of demand elasticities, which are based on small year-to-year variations in taxes, are very similar to values we construct using data for only four large state tax increases in the 1990s. These results suggest we can use regression-based estimates when discussing large tax hikes. We also discuss results from other studies that use methodology similar to the one we outline in the paper.

In section 5, we examine the impact of tax hikes on government revenues. Since taxes are imposed at all levels of government, one consequence of a federal tax hike is to diminish state revenues. In this section, we estimate the extent of the trade-off, using the elasticity-of-demand estimates produced in the previous section. We also consider the regressivity of cigarette excise taxes. Using a time series of individual smoking rates by income quartiles since 1976, we demonstrate that smoking rates among the highest income groups has fallen sharply over time. One reason for this drop is the large decline in smoking rates for the most educated. In the most recent years, we show that the amount of taxes paid decreases monotonically as we move up through the income distribution. Some of the regressivity of taxes is mitigated by the fact that only low-income smokers appear to be sensitive to tax hikes.

In section 6, we examine how taxes may affect cigarette manufacturers. Given their ability to shift tax increases onto consumers, tobacco companies bear little of the burden of a tax. We estimate that for every $\$ 1$ raised in tax revenues, cigarette companies lose only 8 cents in beforetax profits. When viewed in this light, we have a better understanding of why cigarette manufacturers agreed to the Settlement. The Settlement was expected to raise billions of dollars in revenues, but cost the tobacco companies only $\$ 1$ billion per year in pre-tax profits. The cost to companies may be more than offset by the new liability protection that was part of the Settlement, which could be worth a substantial amount. Using daily stock prices from January 1, 1993 to June 30, 1998, we conduct an event study examining how new information about litigation and settlement changed the value of cigarette manufacturers. Some results are not surprising-events that increased the plaintiffs' chances in state Medic- 
aid cases had a statistically significant negative impact on firm value. However, movements toward settlement of the outstanding cases greatly increased stock prices. We then show cumulative returns for cigarette manufacturers relative to the S\&P 500 fell considerably as the prospects for the Settlement collapsed.

In section 7 , we consider the external costs of smoking. Although some argue that current tax revenues exceed the external costs of smoking, these estimates typically exclude one important set of costs: the costs of maternal smoking. These costs have been excluded because most analyses define the economic unit as the family, so that any costs of maternal smoking are by definition not external. We show that the costs of maternal smoking range from $\$ 0.42$ to 0.72 per pack. This makes the question whether these should be considered external critical in any cost-benefit analysis.

\section{A QUICK LOOK AT THE CIGARETTE INDUSTRY}

Throughout the paper, we will make references to facts or events concerning the cigarette industry. Rather than interject these into other parts of the paper, we have decided instead to catalog some of them in this section. We also hope this section will be useful to those who are not familiar with the tobacco industry. As is the case throughout the paper, coverage in this section is by no means exhaustive.

In 1996, Americans spent $\$ 49$ billion on tobacco products, with the vast majority of these dollars used to purchase 24 billion packs of cigarettes. Nearly 99 percent of these cigarettes were produced by only five domestic firms. Although the cigarette industry is still a large sector of the economy, its size has shrunk considerably over time. Since the release of the 1964 surgeon general's report, public-health officials have waged a massive campaign against tobacco use. This campaign has included policies as diverse as restrictions on advertising, anti-smoking public-service announcements, education programs, higher taxes, and smoking bans in public places. In aggregate, these policies appear to have achieved some measure of success. Over the past 20 years, per capita consumption has declined considerably. In Figure 1, we graph per capita cigarette consumption as reported by the Tobacco Institute in its annual publication, The Tax Burden on Tobacco. Beginning in 1976, per capita consumption declined steadily until 1993, with rates stabilizing after then. Per capita consumption in 1993 was at the lowest level since 1943. Most of the decline in consumption is driven by a reduction in the fraction of adults smokers. In Figure 2, we graph the fraction of adults who currently smoke from two sources: The National Health Interview 


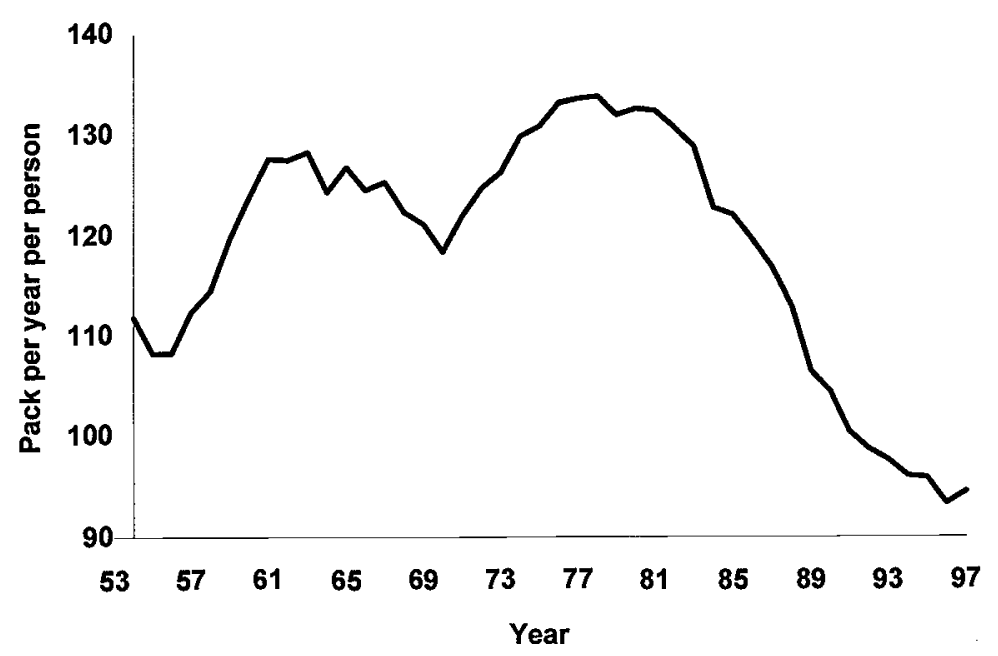

\section{FIGURE 1. Per Capita Cigarette Consumption}

Survey (NHIS) and the Behavioral Risk Factors Surveillance Surveys (BRFSS). Both of these data sets will be defined in more detail later. The NHIS reports adult smoking rates over the 1976-1994 period while the BRFSS rates are from 1985 to 1995. The NHIS numbers show smoking rates declined steadily until 1992, with rates holding steady after. Between 1976 and 1994, smoking rates fell from 36.8 to 25.5 percent, a drop of 30.7 percent. The drop in per capita consumption over this time was about 38 percent, indicating the fall in smoking rates can explain the majority of this drop.

Smoking rates vary systematically across demographic groups. Using various sub-populations of the 1995 BRFSS survey, we calculated the fraction of adults aged 18 and above who smoked at the time of the survey. These rates are reported in Table 1 . Whites, males, workers, and single/divorced individuals smoke at higher rates than their counterparts. Smoking rates decline monotonically with increasing education and income, and whites smoke more than non-whites. Smoking rates are also correlated with age, but the numbers show an interesting pattern. Smoking rates are highest for those under 40 and decline quickly afterwards. That is because most smokers begin regular use at an early age and smoking cessation continues throughout smokers' lifetimes. In Figure 3, we graph the cumulative distribution of the age 


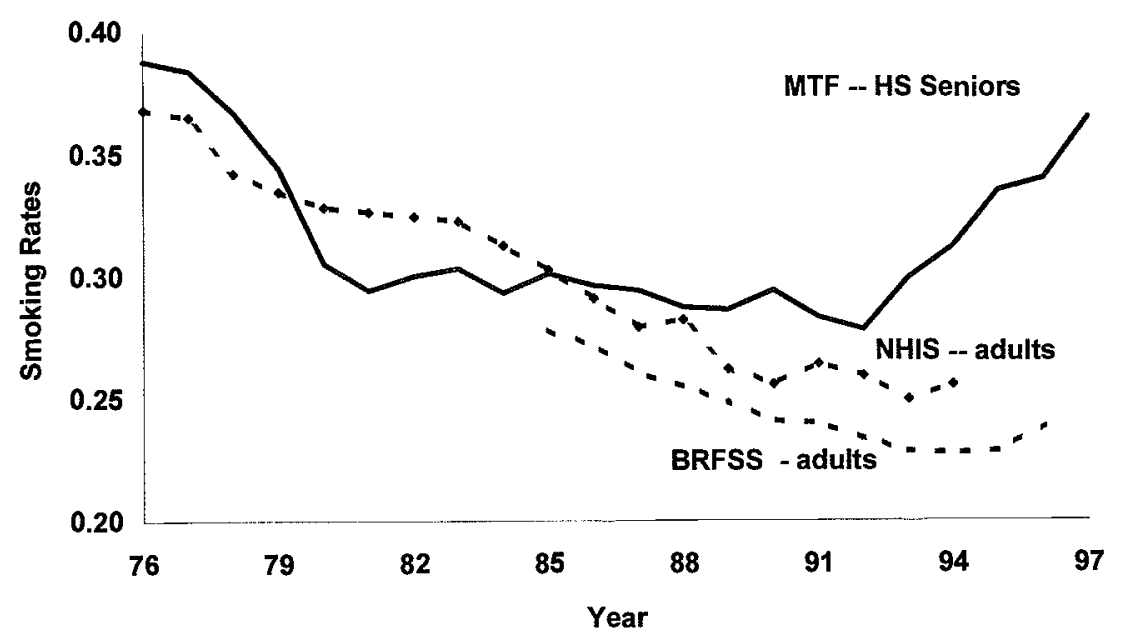

FIGURE 2. Smoking Participation Rates

\section{TABLE 1}

Smoking Rates by Demographic Groups: 1995 BRFSS

\begin{tabular}{|c|c|c|c|c|c|}
\hline Sample & & $\begin{array}{l}\text { Smoking } \\
\text { rate }(\%)\end{array}$ & Sample & & $\begin{array}{l}\text { Smoking } \\
\text { rate (\%) } \\
\end{array}$ \\
\hline \multirow[t]{2}{*}{ Full sample } & & 23.4 & \multirow[t]{5}{*}{ By family income: } & $\leq 15 \mathrm{k}$ & 28.8 \\
\hline & & & & $>15 k, \leq 25 k$ & 27.2 \\
\hline \multirow[t]{3}{*}{ By sex: } & Male & 25.6 & & $>25 k, \leq 35 k$ & 25.6 \\
\hline & Female & 21.5 & & $>35 k, \leq 50 k$ & 23.4 \\
\hline & & & & $>50 \mathrm{k}$ & 17.2 \\
\hline \multirow[t]{5}{*}{ By age: } & $18-24$ & 25.1 & & Missing & 19.1 \\
\hline & $25-39$ & 28.0 & & & \\
\hline & $40-64$ & 25.5 & \multirow[t]{3}{*}{ By marital status: } & Married & 20.2 \\
\hline & $65+$ & 11.6 & & Single & 26.4 \\
\hline & & & & Widowed & 15.9 \\
\hline \multirow[t]{4}{*}{ By race: } & White & 23.7 & & Divorced & 36.7 \\
\hline & Black & 22.5 & & & \\
\hline & Hispanic & 21.7 & \multirow{2}{*}{$\begin{array}{l}\text { By employment: } \\
\text { status: }\end{array}$} & Worker & 25.5 \\
\hline & Other & 22.6 & & Non-worker & 20.1 \\
\hline \multirow[t]{5}{*}{ By education: } & <H.S. & 28.2 & & & \\
\hline & H.S. grad. & 28.1 & & & \\
\hline & Some college & 24.4 & & & \\
\hline & College grad. & 13.8 & & & \\
\hline & Missing & 14.9 & & & \\
\hline
\end{tabular}

The sample size is 109,192 . Sample weights were used in the construction of means. 


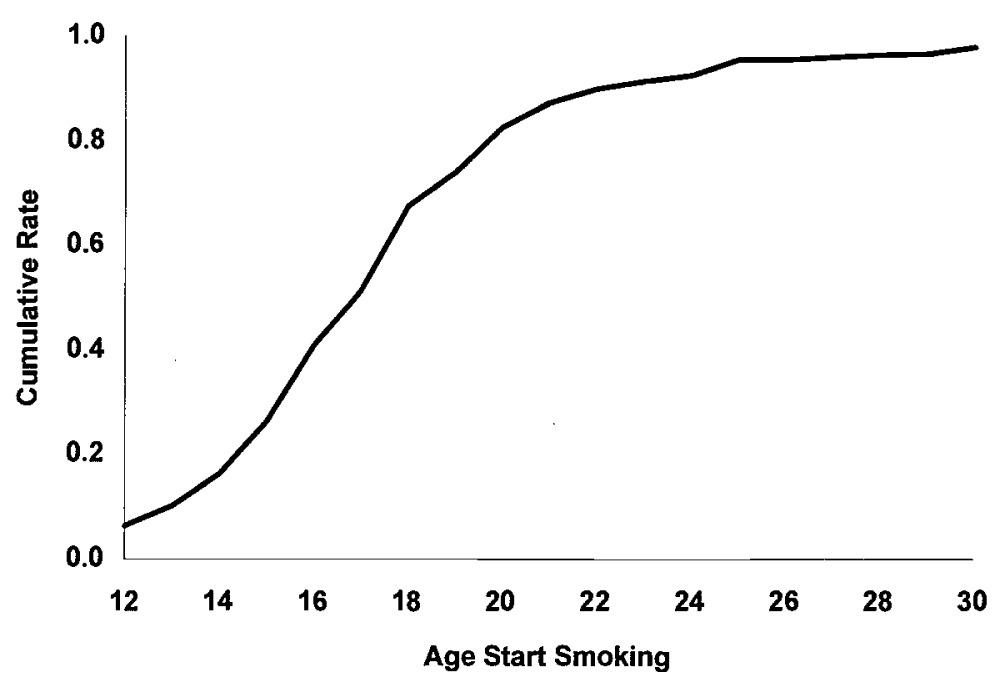

FIGURE 3. Cumulative Smoking Initiation Rates by Age

when smokers report they started smoking fairly regularly, from the Tobacco Use Supplements (TUS) to the September 1992, January 1993, and May 1993 Current Population Survey (CPS). Nearly 75 percent of all adult smokers started smoking regularly by the age of 19 , and over 40 percent of ever smokers started at ages 16-18. Note that contrary to some press reports, a great many smokers pick up the habit after their teen years.

In 1997, the average retail price of cigarettes varied from $\$ 1.46$ in Kentucky to $\$ 2.65$ in the state of Washington. Most of the variation in retail prices is due to differences in excise taxes across geographical areas. Tobacco products are taxed at the local, state, and federal level. In the fiscal year ending in June 30,1997, the Tobacco Institute estimates revenues from these three sources of tobacco taxes totaled $\$ 13.2$ billion, with $\$ 7.3$ billion coming from states, $\$ 5.7$ from the federal tax, and only $\$ 0.2$ billion from local sources. Overall, 96 percent of these revenues were from cigarette taxes. The federal tax on cigarettes is currently $\$ 0.24$ / pack, and state taxes range from a low of $\$ 0.025 /$ pack in Virginia to a high of $\$ 1.00 /$ pack in Alaska and Hawaii. The federal tax has only been increased three times over the past 45 years, staying at $\$ 0.08$ /pack from 1952 to 1983 and rising to $\$ 0.16 /$ pack in 1983, \$0.20/pack in 1991 and $\$ 0.24 /$ pack in 1993. In contrast, state tax changes have been frequent and varied. Since 1975, there have been 173 nominal changes in state tax rates, ranging from a 5-cent/pack drop to a 50-cent/pack increase. The 
frequent tax changes at the state level will be used below to help identify the impacts of changing excise taxes on demand.

One of the most significant innovations in the tobacco industry has been the introduction of generic or discount brands. First introduced in 1980 by Liggett, generic cigarettes were sold in plain packages at prices 25 to 40 percent below name-brand cigarettes. In 1984, Reynolds introduced name-brand discount cigarettes, priced between generic and traditional brands. Between 1980 and the early 1990s, price hikes on branded cigarettes outstripped the general inflation rate. As a result, the discount market grew steadily over time, representing 36 percent of cigarettes sold by 1993. In response to the growth of the discount market, Philip Morris announced on April 2, 1993 (known as Marlboro Friday) that it would drop the price on its flagship brand Marlboro by 40 cents/pack (about a 20-percent drop in price). The price cut was quickly matched by other cigarette manufacturers, and Philip Morris extended the price break to other brands. Consequently, the generic market shrank to less than 30 percent of the total. The impact of generic cigarettes on prices can be seen in Figure 4, where we graph the average retail price for cigarettes over time in 1997 dollars. Note that through 1993, real retail prices increased considerably, but since then prices have been constant. It is interesting to note that smoking rates and aggregate consumption stabilized at the time when the increases in real cigarette prices stopped. In Figure 4 we also graph the real tax (state+federal). Although there

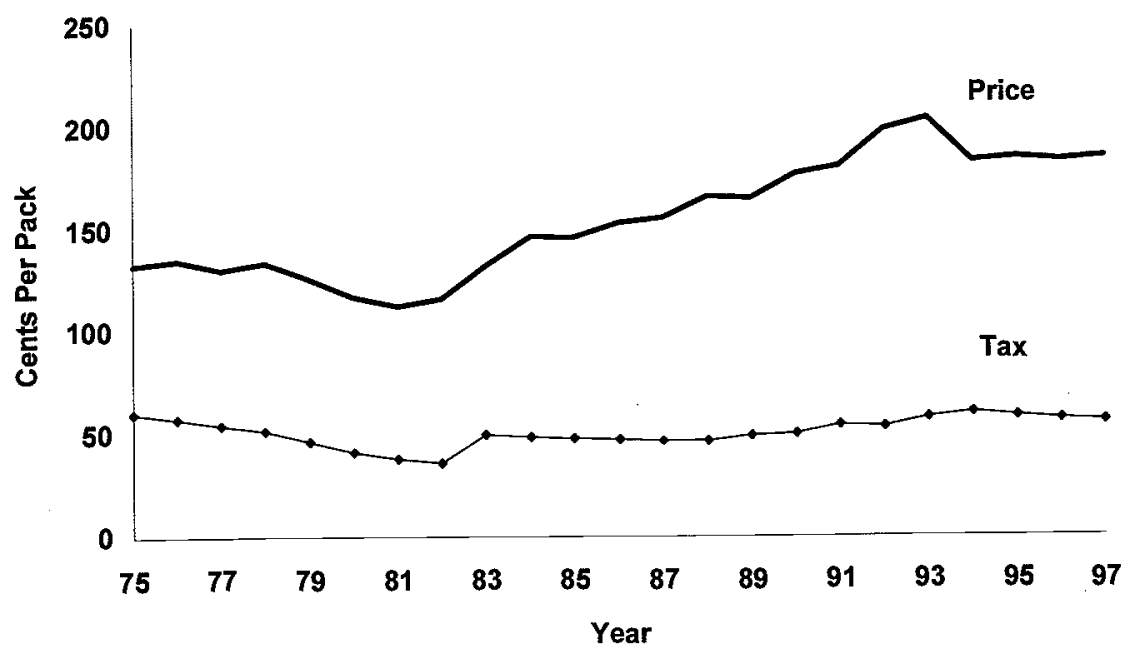

FIGURE 4. Real Per-Pack Prices and Taxes 
have been considerable changes in the nominal cigarette excise tax, the changes have typically just replaced the value of the tax that had been eroded by inflation. Note that the real value of taxes in 1995 is about where it was in 1976; therefore, as the real price of cigarettes has increased over time, but real tax has remained flat, the fraction of the retail price that goes to taxes has declined.

\section{A BRIEF OUTLINE OF RECENT TOBACCO CONTROL LEGISLATION}

In the past, anti-smoking programs have been adopted at all levels of government. Excise taxes are imposed at the local, state, and federal level. The federal government has banned advertising on television, and in recent years the FDA has moved to restrict advertising aimed at teenagers. State and local governments have adopted laws restricting smoking in public places, whereas the federal government has proposed, but never adopted, a complete ban on workplace smoking. In the past, these efforts have never been coordinated. One aspect of recent tobacco control proposals, particularly the Settlement, was the far-reaching nature of the programs. ${ }^{5}$

The Settlement was a true compromise between the states and the tobacco industry, each side gaining only part of what it wanted when it came to the negotiating table. Under the Settlement, the states would gain significant payments from the industry, the governments would obtain greater control over cigarette production and advertising. The Settlement raised prices to pay industry fines, restricted advertising, extended the authority to regulate nicotine to the FDA, and instituted a near-complete ban on workplace smoking. In return, the industry would gain important liability protection and some antitrust immunity.

Under the Settlement, the industry was expected to pay an initial lump-sum fee of $\$ 10$ billion. Over the next 25 years, payments would include yearly fines of set payment amounts. In the first year of the agreement the industry would pay $\$ 8.5$ billion, with payments increasing to $\$ 15$ billion per year by year 5 and remaining at that level for the rest of the agreement. Future payments would be adjusted according to the volume of cigarette sales in that given year, the reduction being essentially equal to the reduction in consumption from the base year. The agreement also required the tobacco firms to pass on to consumers the full cost of the payments. This payment structure has two obvious effects: the Settlement legislated that consumers would pay nearly all of

${ }^{5}$ For a more detailed discussion of many economic aspects of the Settlement, see the excellent piece by Bulow and Klemperer (forthcoming). 
the burden of the tax, and the volume-adjusted payments are equivalent to an excise tax on cigarettes.

An important objective of the Settlement was to reduce youth smoking. Some of the provisions designed to achieve this goal were a ban on all outdoor advertising of cigarette products, use of industry payments to increase enforcement of youth tobacco access laws, and lookback penalties that imposed significant monetary fines on the tobacco industry if underage tobacco use did not fall by a prescribed amount over the next 10 years. The interest in how taxes affect teen smoking is driven primarily by two factors. First, as we saw in Figure 3, the majority of smokers begin consuming cigarettes during teen years. Second, the interest in teen smoking has been heightened by evidence indicating that, unlike the overall smoking rate, teen smoking remained relatively constant over the 1980s and the early 1990s. In Figure 2, we indicate smoking rates for high-school seniors from the Monitoring the Future Project (MTFP). ${ }^{6}$ Notice that in the NHIS data, smoking rates declined monotonically from 1976 to 1990, and the numbers have stabilized since that time. In contrast, the MTFP data show a sharp drop in teen smoking rates from 1977 to 1980 , steady rates from 1980 to 1992 , and a massive increase in rates ever since. In fact, the MTFP data show an 8.7-percentage-point increase in teen smoking rates over the past five years (Monitoring the Future Project News Release, December $19,1997)$. For the lookback penalties, the agreement called for a 30-percent reduction in youth smoking by the fifth year and a 60-percent reduction by the tenth year of the agreement. For every percentage point of nonattainment the industry would be fined an additional $\$ 80$ million. ${ }^{7}$

The Settlement resolved a great deal of uncertainty for the industry. The most important aspect of the agreement from the industry standpoint was the liability protection. The civil liability provision would resolve all punitive damage claims for past and future conduct in suits claiming injury or damage caused by industry conduct. In addition, the agreement would disallow any class action suits against the industry. Finally, the Settlement imposed an annual aggregate cap for judgements and settlements of 33 percent of the annual industry base payment. Some of these payments were also credited against the yearly settlement

${ }^{6}$ The smoking rates from the NHIS and BRFSS are roughly comparable in that respondents are asked to identify whether they are current smokers. Smoking rates for the MTFP represent the fraction of high-school seniors who have smoked in the past 30 days. Daily use rates from the MTFP show comparable trends to the 30 -day use rate, but are obviously much smaller than the numbers reported in the figure.

7 The lookback penalty was capped at $\$ 2$ billion in any year. Estimates of youth smoking rates will be taken from the Monitoring the Future survey designed and implemented by the University of Michigan. 
payments, again moving some of the cost of the settlement away from firms and onto current smokers.

The Settlement also contained a broad antitrust exemption for the industry. The purpose of the exemption was to enable the industry to coordinate its effort to reduce tobacco use by children; however, the antitrust exemption might have enabled the tobacco firms to coordinate their activities and discuss pricing arrangements that would lead to higher profits for the industry and higher cigarette prices for consumers (Federal Trade Commission, 1997).

The McCain bill was similar to the Settlement in many ways. It contained many of the same provisions such as industry payments, lookback penalties, advertising restrictions, and FDA authority to regulate tobacco products. The main difference was that the McCain bill imposed larger fines on the industry with less liability protection. The McCain bill, just like the Settlement, called for an initial industry payment of $\$ 10$ billion; however, the following yearly payments were significantly larger. In the first year, the industry would pay $\$ 14.4$ billion. The payments would increase gradually to $\$ 23.6$ billion by the fifth year of the agreement. Beyond the fifth year, the payment would be calculated using a formula to adjust for changes in volume. The lookback penalties were also significantly higher in the McCain bill. If youth smoking rates did not fall to the prescribed level, the lookback penalty would be based on the level of non-attainment. The fine was set at $\$ 80$ million for each percentage point of non-attainment between 0 and 5 . If non-attainment was greater than 5 percentage points, the fine increased to $\$ 400$ million plus $\$ 160$ for each percentage point of non-attainment in excess of 5 . The maximum lookback penalty under the McCain bill was $\$ 4$ billion, two times greater than what was agreed to in the Settlement.

Initially the McCain bill provided limited liability protection for the industry. Unlike the Settlement, the McCain bill permitted class action suits against the industry. Under the bill, the state lawsuits would be settled and there would be an annual ceiling of $\$ 6.5$ billion on private legal claims. However, even these limited liability provisions were eliminated during the debate on the bill in the Senate. The McCain bill died in the Senate on June 17, 1998, almost exactly one year after the historic Settlement was announced.

\section{THE IMPACT OF EXCISE-TAX INCREASES ON THE MARKET FOR CIGARETTES}

In this section, we examine the immediate impact of tobacco tax increases-particularly, how these tax changes alter demand for the 
product. The analysis would be more straightforward if recent tobacco control policies proposed excise-tax hikes, but, as noted in the previous section, the major policies considered do not actually increase taxes, but rather impose quantity-adjusted fines. Therefore, we start the next section by drawing parallels between the effects of taxes and fines.

\subsection{What is the Effect of Taxes on Retail Prices for Cigarettes?}

In textbook economic models, excise taxes are predicted to increase aftertax prices by an amount less than the value of the tax, leading consumers and producers to share the burden of the tax. These models typically assume the output market is perfectly competitive. In markets without perfect competition, the size of the price change depends critically on the shape of the demand curve. For example, if demand in a monopolized industry is linear, an excise tax of $t$ dollars per unit will increase the price by less than $t$. In contrast, if demand is isoelastic in monopolized industries, the same excise tax can increase after-tax prices by an amount larger than $t$.

A number of authors have used the changes in price after tax increases to test whether market power exists in the cigarette industry (Harris, 1987; Sumner, 1981; Sullivan, 1985; Stern, 1987; Barnett, Keeler, and Hu, 1995; Keeler et al., 1996). These works find that nearly all and sometimes more than 100 percent of an excise tax hike is passed on to consumers in the form of higher retail prices. It is easy to construct a simple econometric model that mimics the results of these earlier papers. Given the variation across states in the timing and size of tax changes, we can examine how average retail prices respond to changes in state excise taxes. We use states that have changed taxes as a treatment group, and compare price movements over time for this group with those for states with no change in nominal rates. Data on average state retail cigarette prices are taken from The Tax Burden on Tobacco, published by The Tobacco Institute (1998). Tax rates are measured as state plus federal excise taxes on cigarettes. The prices and tax rates are measured as of June 30 in each year. We take data from the 12-year period 1985-1996 for all states and the District of Columbia. ${ }^{8}$ The basic model we estimate is of the form

$$
\operatorname{PRICE}_{i t}=\operatorname{TAX}_{i t} \beta_{1}+\mu_{i}+v_{t}+\epsilon_{i t}
$$

8 The Tobacco Institute data go back as far as 1954 , but we restricted our attention to the last 12 years for two reasons. First, that time period is most relevant for current policy debates. Second, it closely matches the years covered in our individual-level data set that we use below. 
TABLE 2

OLS Estimates, Retail Price Model: Tobacco Institute Data

\begin{tabular}{|c|c|c|c|c|}
\hline \multirow[b]{2}{*}{$\begin{array}{l}\text { Independent } \\
\text { variable }\end{array}$} & \multicolumn{2}{|c|}{$\begin{array}{c}\text { Average state retail } \\
\text { price, } \\
1985-1996\end{array}$} & \multicolumn{2}{|c|}{$\begin{array}{c}\text { Net retail price in } \\
\text { Tennessee, } \\
\text { 1970-1994 }\end{array}$} \\
\hline & $\begin{array}{l}\text { Nominal } \\
\text { (1) }\end{array}$ & $\begin{array}{l}\text { Real } \\
\text { (2) }\end{array}$ & $\begin{array}{l}\text { Nominal } \\
\text { (3) }\end{array}$ & $\begin{array}{c}\text { Real } \\
(4)\end{array}$ \\
\hline Nominal/real tax & $\begin{array}{c}1.01 \\
(0.04)\end{array}$ & $\begin{array}{c}0.92 \\
(0.04)\end{array}$ & & \\
\hline Nominal/real wholesale price & & & $\begin{array}{c}1.07 \\
(0.02)\end{array}$ & $\begin{array}{c}0.86 \\
(0.04)\end{array}$ \\
\hline$R^{2}$ & 0.972 & 0.933 & 0.989 & 0.963 \\
\hline Observations & 612 & 612 & 25 & 25 \\
\hline
\end{tabular}

Standard errors in parentheses. Real prices in 1997 cents/pack. Models in columns (1) and (2) control for state effects.

where PRICE is average retail price per pack of cigarettes in state $i$ in year $t$ measured in cents, $\operatorname{TAX}_{i t}$ is the total per pack tax (state+federal) measured in cents, and $\epsilon_{i t}$ is a random error. We estimate the model controlling for both state $\left(\mu_{i}\right)$ and year $\left(v_{t}\right)$ effects. The state effects control for any permanent differences in prices across states. For instance, some states have higher (or lower) average prices over the entire sample. The year effects purge shocks to price that are common to all states but may vary across years. These would include such factors as federal tax changes, changes in wholesale prices, or changes in pricing strategies brought about by the emergence of generic cigarettes. ${ }^{9}$ Since we dummy out both dimensions of the data set, the coefficient on $\beta$ is determined solely by changes in taxes and price within in a state over time.

We estimate two versions of the model. In model (1), we use nominal prices and taxes, since states change nominal excise tax rates. In model (2), we use the CPI to translate all prices and taxes into real 1997 dollars. The results for these two models are reported in the first two columns of Table 2. Notice the basic results reported in previous papers are replicated in this simple analysis of covariance. In model (1), a nominal tax change of 1 cent is expected to increase average retail prices by 1.01 cents. The coefficient on real tax in model (2) is 0.92 . These results

${ }^{9}$ Wholesale prices are set at the national level. Therefore, the year effect included in the model will capture the effect of any change in wholesale prices that may take place during a given year. 
indicate that excise taxes are passed completely on to consumers in the form of higher retail prices. ${ }^{10}$

These results may not be informative about the impact of recent tobacco control initiatives, since those policies do not rely on higher excise taxes. As we noted in section 3, most recent tobacco control initiatives, such as the Settlement or the McCain bill, raise prices through a quantity-adjusted yearly fine assessed on cigarette manufacturers, who are required to raise the price of cigarettes to pay for it. In principle, the fine should work similarly to an excise tax, so long as the retail market is competitive. However, in some analyses of the Settlement and the McCain bill, industry observers speculated that because the fine is levied early on in the distribution network, retail prices would be much higher than predicted by the administration and other researchers. This argument suggested that at all points in the distribution chain, firms would tack on margins to the wholesale price increase, sharply inflating the final cost of the quantity-adjusted fines.

To test whether the quantity-adjusted fine is equivalent to an excise tax, we examine the degree to which retail prices move as wholesale prices are increased. Since wholesale prices are national prices, we need to retreat from our state-panel data set to a strict time-series sample; however, a national time series is corrupted by changing state taxes. As a compromise, we use a time series relatively free from effects of state tax changes-retail prices in Tennessee. Tennessee was chosen because its state tax was a constant 13 cents/pack over the $1970-1994$ period. ${ }^{11}$ The econometric model we estimate is rather simple: we regress retail prices, net of state and federal taxes, on wholesale prices per pack of cigarettes. Data on wholesale prices is taken from Table 40 of U.S. Tobacco Statistics published by the Economic Research Service, United States Department of Agriculture. The data are available to download from a Web site maintained at Cornell University (http://usda.mannlib.cornell.edu). We used the wholesale price that was in place on June 30 of the given year to best match the retail price data from the Tobacco Institute. As with the statelevel panel data, we estimate two models: one with nominal and one with real prices.

The results using data from Tennessee are reported in the last two columns of Table 2 . These results show that changes in wholesale prices are translated dollar for dollar into higher retail prices. The results of

10 Manufacturers' ability to pass tax hikes onto consumers has diminished over time. Estimating model (1) from Table 2 for the past 15, 20, and 25 years, the coefficients (standard errors) on nominal tax are $1.05(0.03), 1.10(0.03)$, and $1.13(0.02)$ respectively.

11 The data set for this sample stops in 1994 because we were unable to obtain data on wholesale prices for the most recent years. 
these models suggest that although proposals like the Settlement and the McCain bill do not directly raise excise taxes, the quantity-adjusted fines can be treated as an excise tax. Throughout the rest of the paper, we then examine the impact of higher excise taxes.

\subsection{What Is the Impact of Higher Taxes on Demand?}

There is a large literature in economics that has examined whether smoking is correlated with taxes and prices. These studies vary in the type of data (individual-level versus aggregate data), the time periods under consideration, and the covariates of interest (taxes versus price). The results of these studies have been reviewed in a number of sources, including Manning et al. (1991), Viscusi (1992), and Grossman, Sindelar, Mullahy, and Anderson (1993), the most comprehensive review being contained in Chaloupka and Warner (1998). Nearly every study finds smoking declines in the face of higher taxes and/or prices, but the results do vary across surveys. Not all demand elasticities are created equal, so not all studies should be given equal weight. Rather than try to glean from this literature the "correct" elasticity of demand, we instead outline a few characteristics that we would like to see in these studies, and then generate estimates using two different types of data: aggregate statelevel and individual-level.

The first characteristic we would prefer to see is the use of tax, as opposed to price, as the covariate of interest. Most demand estimates reviewed in Chaloupka and Warner (1998) use as the covariate of interest some measure of cigarette price, with prices varying across geographic areas. Intuitively, this may make sense, since the ultimate goal is to estimate a demand elasticity. There are, however, four reasons to prefer estimates based on variations in taxes. First, the primary reason for geographic variation in prices is differences in tax rates; thus it seems more direct to use this variation as the source of identification in models. Second, taxes are measured with much less error than prices. Most price measures are constructed using a sample of products and measure only shelf prices, which do not reflect final prices if discount coupons are available. These coupons are now widely used in the industry. As another example, teens almost exclusively smoke name-brand cigarettes (Centers for Disease Control, 1992). An average price that includes a large market share for generics will not measure the effective price for teens very well. Third, estimates based on tax directly identify the likely impact of government intervention. Fourth, price is an outcome of a market process, not an exogenous factor; therefore, the differences in price across states may represent more than just differences in tax rates, possibly making the coefficient on price subject to an omitted-variables 
bias. Since tax is arguably a more exogenous factor, the coefficient on this variable should be less subject to such a bias.

The second characteristic we would like to see is the use of pooled time-series cross-sectional data sets as opposed to just cross-state variation in taxes or prices. Since excise taxes on cigarettes vary across states, in principle we can use the cross-state variation in taxes to identify the models of interest. Nearly all papers that use individual-level data reviewed by Chaloupka and Warner use this type of identification procedure. We believe utilizing cross-state variation in taxes or price may have some shortcomings. If the level of taxation in a state is correlated with some underlying characteristics of that state, then cross-sectional correlations may be subject to an omitted-variables bias. Consider the case of three tobacco-producing states: Kentucky, North Carolina, and Virginia. In 1997, these states ranked first, fourth, and fourteenth, respectively, in per capita aggregate consumption and had the three lowest state tax rates. Can we infer from these numbers that taxes reduce smoking, or do the same factors that lead states to have high consumption levels (their tobacco-producing history) also discourage high excise taxes? In view of such difficulties, we prefer to use pooled time-series cross-section data sets when estimating demand elasticities. The models can be thought of as quasi-natural experiments where smoking levels in states before and after tax increases (the treatment groups) are compared with changes in rates for states that did not change their taxes (the control). Panel data also give us the ability to control for permanent differences across states in consumption by using state fixed effects. These models allow us to control for the possibility that there may be an underlying correlation between the average level of taxation and consumption in the sample that is not causal.

The difficulty with using cross-state correlations is present in crosscountry comparisons as well. Many European countries have both higher cigarette taxes and higher consumption rates than the U.S. Some may point to this comparison as evidence that higher taxes will not reduce demand. In fact, although taxes have been shown to reduce smoking, taxes explain but a small variation in smoking rates across jurisdictions. The real question is not whether differences in taxes can explain differences in the levels of smoking across areas, but whether higher taxes in one area will reduce smoking.

We are not the first to make these first two points. The use of taxes as the covariate of interest in a treatment-control design is convincingly made by Cook and Tauchen (1982) in their analysis of liquor taxes. This is not to say that cross-sectional models cannot generate an unbiased estimate of the elasticity of demand. Rather, we think models using cross- 
sectional identification need to consider the problem of omitted-variables bias much more seriously than has been done in the past.

Finally, to be informative about current proposals, samples should include data relevant to the time period. As the discussion in section 2 indicates, smoking levels have changed considerably over time. The types of people who smoke today are very different from those 30 years ago. We present evidence for this point in section 5. Consequently, even high-quality results generated from older samples may not be informative about current conditions. For example, the earliest cigarette demand study using individual-level data is that of Lewit, Coate, and Grossman (1981). Although the structure of many subsequent papers follows this paper as the model, the estimates from this paper may not be informative about today's smokers, since it used data from 1966-1970.

In the next three sub-subsections, we report results generated from models with pooled time-series/cross-sectional data sets using tax as the covariate of interest and using the most recent data available. In section 4.2.1 below, we produce results using aggregate state-level consumption data. In section 4.2.2, we generate tax elasticities from individual-level data. Finally, in section 4.2 .3 we summarize results from other studies that use similar methodologies but have different data sets and/or populations. In the end, we produce a consistent set of results across models and samples.

4.2.1 Estimates Using Aggregate Data In this sub-subsection, we use a basic panel data set on aggregate cigarette consumption at the state level to estimate the effect of taxes on demand. The basic data source for nearly all variables is the Tobacco Institute's annual volume The Tax Burden on Tobacco. The demand measure in these reports is the per capita number of packs of cigarettes consumed per year, with fiscal years ending June 30 . State and federal taxes are measured as of that date as well. To provide a long series of data by state, we use data for the 12-year period 1985-1996 for all states and the District of Columbia. The basic model we estimate is of the form

$$
Q_{i t}=\operatorname{TAX}_{i t} \beta_{1}+X_{i t} \alpha+\mu_{1 i}+\mu_{2 i} \operatorname{TIME}_{t}+v_{t}+\epsilon_{i t}
$$

where the dependent variable is log per capita consumption in state $i$ in year $t$, and TAX $\mathrm{it}_{\mathrm{it}}$ is the tax (state+federal) in constant 1997 cents per pack. The vector $X$ contains a set of covariates that describe the state's adult population. Using the annual demographic files from the March CPS, we calculate for $X$ the fractions of adults aged 18 and up that are Black, that are Hispanic, that have less than 12 years, 12 years, and 13-15 years of 
education, and that are in the 18-25, 26-39, and 40-64 age groups. We also added the log real per capita income. ${ }^{12}$ We include state $\left(\mu_{1 \mathrm{i}}\right)$ and year $\left(v_{t}\right)$ effects in the model, and, given the limited set of controls, we add state-specific linear time trends. The fixed-effects model is intuitively appealing in this context, since most of the variation in consumption is between states and not within states over time. Using a simple variance decomposition, it is easy to show that 70 percent of the variation in $Q_{i t}$ is between states, whereas only 30 percent is within-state variation over time.

To facilitate comparisons of our estimates with those from other papers, we translate the estimate from equation (2) into price elasticities of demand. Since retail prices $P$ are a function of the taxes levied on cigarettes, the effect of taxes on smoking behavior can be expressed as $\partial Q / \partial T$ $=(\partial \mathrm{Q} / \partial \mathrm{P})(\partial \mathrm{P} / \partial \mathrm{T})$, where $\partial \mathrm{P} / \partial \mathrm{T}$ is the change in price with respect to a change in tax rates. The price elasticity of demand is defined as

$$
e_{d}=\frac{\partial Q / \partial T}{\partial P / \partial T} \frac{\bar{p}}{\bar{q}},
$$

where $\bar{p}$ and $\bar{q}$ are the sample means of retail price and consumption respectively. Using results from Table 2 above, $\partial \mathrm{P} / \partial \mathrm{T}$ is approximately 1 , and the sample means of price and per capita consumption are 175 cents and 105 packs.

The results from the basic model are reported in the first column of Table 3 . The coefficient on tax is -0.254 and is precisely estimated. This coefficient translates into a demand elasticity of approximately -0.42 . In a comprehensive review of demand-elasticity estimates, Chaloupka and Warner (1998) note that studies using aggregate data generate demand estimates clustered around -0.4 . In column (4), we use real prices instead of tax and we estimate an elasticity of $-0.294,31$ percent smaller than the estimate generated using tax as the covariate. Although many papers generate estimates that are similar regardless of whether price or tax is used, in this case, price and tax are not interchangeable. Part of the reason may be the changes in pricing patterns brought about by generic cigarettes.

The estimates of the effect of tax on consumption in column (1) of Table 3 are generated from relatively small changes in state taxes. During the time period of our analysis, there were 137 nominal state tax changes, with the median and mean values 5 and 7.5 cents, respectively. Consequently, the results in Table 3 may not be informative about the large tax changes contained in many recent tobacco control proposals.

12 The data for the real per capita income came from the Bureau of Economic Analysis, Regional Accounts Data, Personal Income Tables, 1958-1996, downloaded from http:// www.bea.doc.gov. 
TABLE 3

OLS Estimates, Log Per Capita Consumption Model, Tobacco Institute Data, 1985-1996

\begin{tabular}{|c|c|c|c|c|c|c|}
\hline \multirow{3}{*}{$\begin{array}{l}\text { Independent } \\
\text { variable }\end{array}$} & \multicolumn{6}{|c|}{ Coefficients (standard errors) on } \\
\hline & \multicolumn{3}{|c|}{ Real tax } & \multicolumn{3}{|c|}{ Real price } \\
\hline & (1) & (2) & (3) & (4) & (5) & (6) \\
\hline Current value & $\begin{array}{c}-0.254 \\
(0.037)\end{array}$ & $\begin{array}{c}-0.165 \\
(0.040)\end{array}$ & $\begin{array}{c}-0.173 \\
(0.041)\end{array}$ & $\begin{array}{c}-0.176 \\
(0.027)\end{array}$ & $\begin{array}{c}-0.176 \\
(0.027)\end{array}$ & $\begin{array}{c}-0.167 \\
(0.029)\end{array}$ \\
\hline 1-year lag & & $\begin{array}{c}-0.215 \\
(0.413)\end{array}$ & $\begin{array}{c}-0.188 \\
(0.047)\end{array}$ & & $\begin{array}{c}-0.027 \\
(0.032)\end{array}$ & $\begin{array}{r}-0.031 \\
(0.032)\end{array}$ \\
\hline 2-year lag & & & $\begin{array}{c}-0.061 \\
(0.045)\end{array}$ & & & $\begin{array}{c}-0.017 \\
(0.033)\end{array}$ \\
\hline Price elasticity & $\begin{array}{c}-0.424 \\
(0.062)\end{array}$ & $\begin{array}{c}-0.635 \\
(0.074)\end{array}$ & $\begin{array}{c}-0.705 \\
(0.090)\end{array}$ & $\begin{array}{c}-0.294 \\
(0.045)\end{array}$ & $\begin{array}{c}-0.337 \\
(0.058)\end{array}$ & $\begin{array}{c}-0.359 \\
(0.072)\end{array}$ \\
\hline$R^{2}$ & 0.975 & 0.977 & 0.977 & 0.975 & 0.975 & 0.976 \\
\hline
\end{tabular}

Standard errors in parentheses. The dependent variable is the log per capita consumption. There are 612 observations in each model. The mean price is $\$ 1.75 /$ pack, and the mean per capita consumption is 105. All models include year effects, state effects, state-specific time trends, and log per capita consumption, plus measures of the fraction of adults in three age, three education, and two race groups.

A number of states have initiated tax changes in the past 8 years. In the first three columns of Table 4, we report the states with the largest four tax changes during the early to mid-1990s. We can learn something about how these non-marginal tax changes alter demand by viewing the states' time-series path of log consumption against national figures. In Figures $5 a-d$, we graphically compare the state figures for these four experiments with national values for per capita consumption. The vertical line in each

\section{TABLE 4}

Estimated Long-Term Cigarette Demand Elasticities for Selected States, Tobacco Institute Data

\begin{tabular}{lccccc}
\hline State & $\begin{array}{c}\text { Year of } \\
\text { tax hike }\end{array}$ & $\begin{array}{c}\text { Size of tax change, } \\
\text { nominal (cents) }\end{array}$ & $\% \Delta Q$ & $\% \Delta P$ & $\epsilon_{d}$ \\
\hline AZ & 1994 & 40 & -18.5 & 22.4 & -0.83 \\
MA & 1993 & 25 & -13.3 & 14.3 & -0.93 \\
MI & 1994 & 50 & -20.5 & 23.9 & -0.86 \\
NY & 1993 & 27 & -12.6 & 5.3 & -2.38 \\
\hline
\end{tabular}

Percentage changes are measured over a three year period. The initial point is one year prior to the tax change and the end point is three years later. 

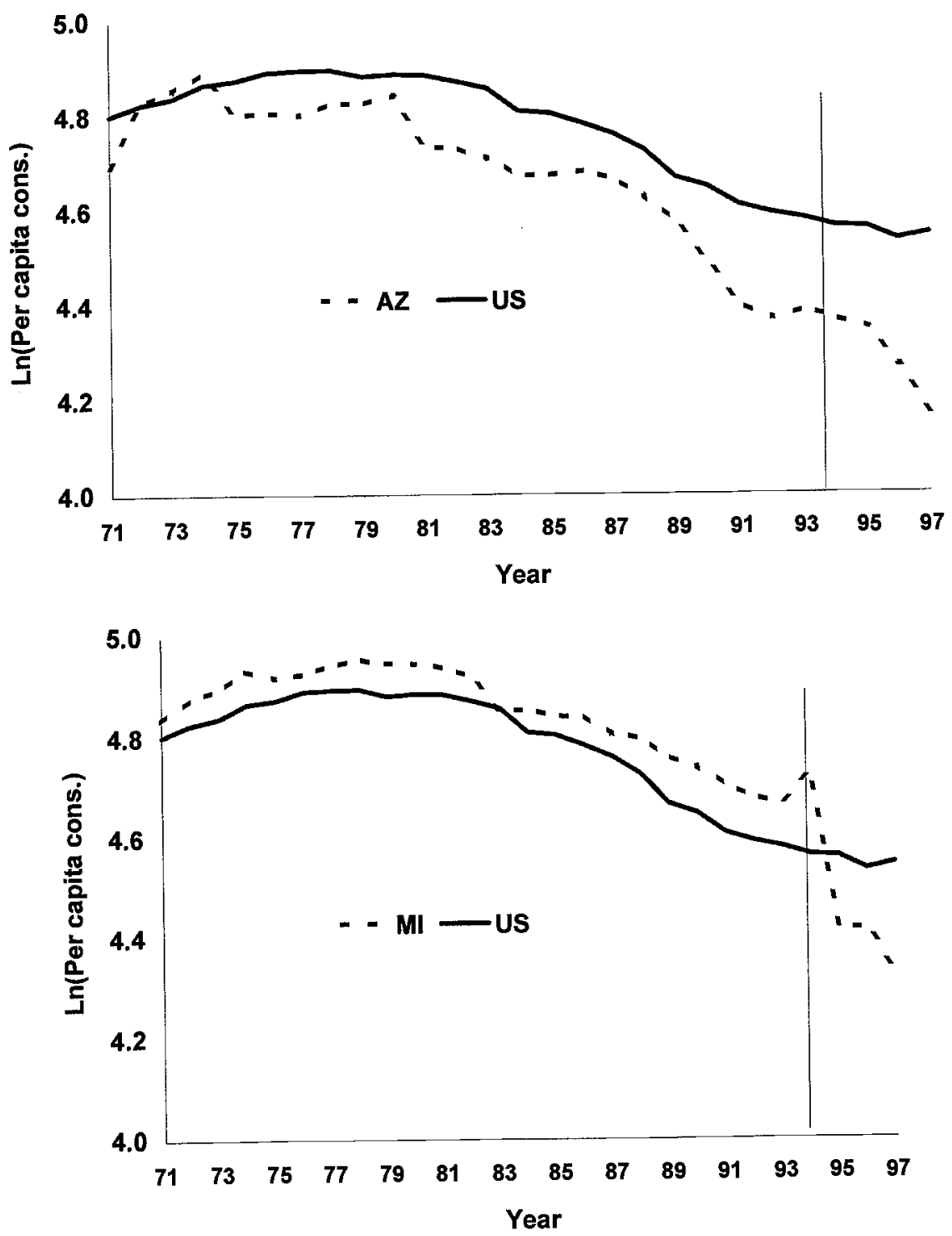

FIGURE 5. Per Capita Consumption: (a) AZ vs. U.S.; (b) MI vs. U.S.; (c) MA vs. U.S.; (d) NY vs. U.S. 

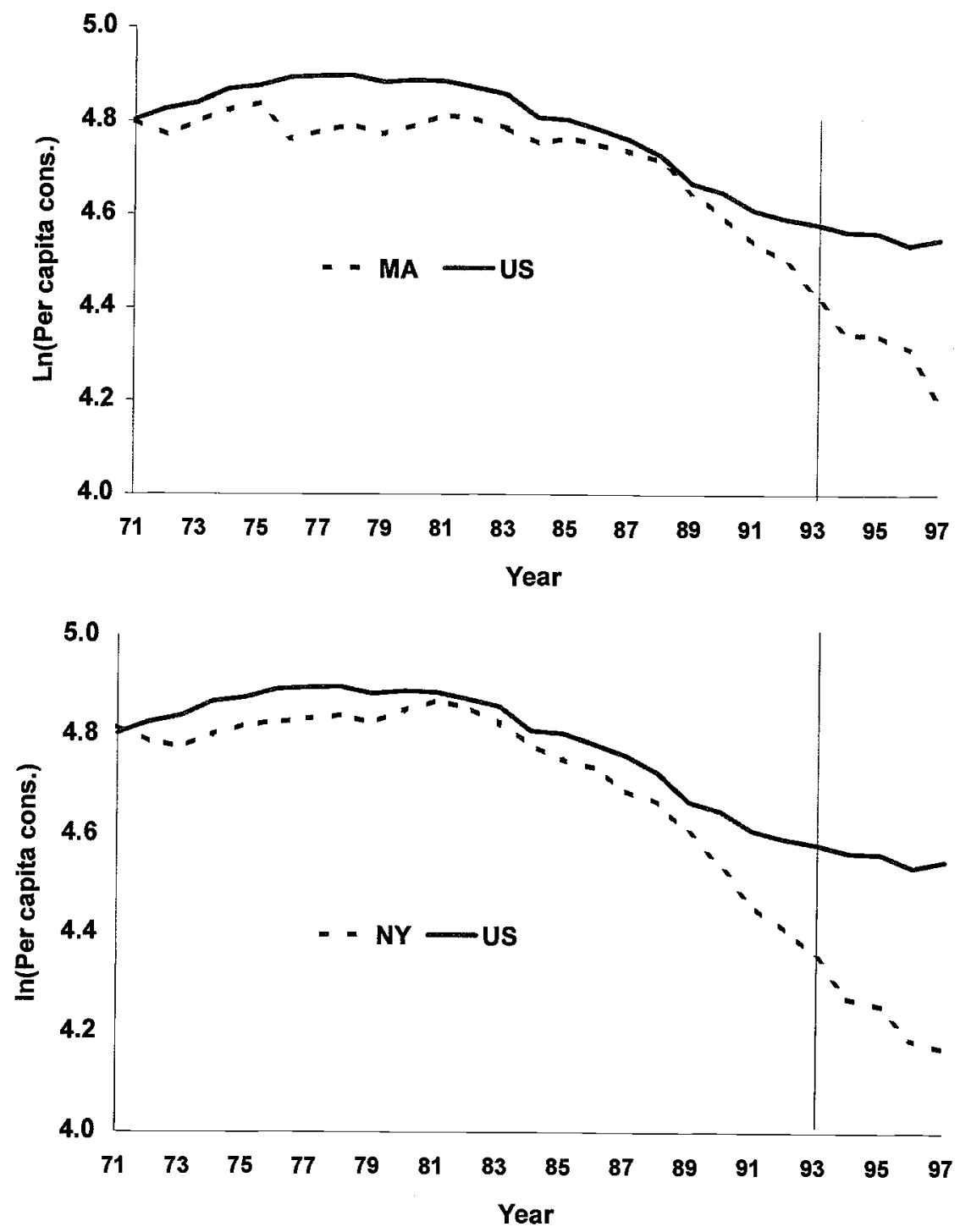

FIGURE 5. cont. 
graph represents the year the tax hike became effective. Two things are evident from these graphs. First, there is a noticeable drop in per capita consumption in states after a large tax change. Second, in all four states, consumption continues to fall relative to aggregate U.S. consumption for the first few years after the tax increase. These results suggest that the full effect of a tax change may take a few years to fully develop.

The estimates in column (1) of Table 3 are short-term elasticities in that they only consider the contemporaneous covariance between tax and consumption. Smoking cessation and initiation are dynamic processes that may take time to mature. This process has been modeled formally in a rational-addiction framework by Becker and Murphy (1988), and tests of these models are contained in Becker, Grossman, and Murphy (1991) and Chaloupka (1991). These papers show that long-term elasticities from rational-addiction models of cigarette demand, which include past measures of cigarette consumption, lead to a greater price responsiveness.

A long-term elasticity can be estimated in our basic regression model by adding additional lags of tax rates into the equations. These results are presented in columns (2) and (3) in Table 3. Notice that in column (3), all three tax measures are statistically significant. Adding the three coefficients together and translating the sum into an elasticity, we calculate a three-year elasticity of -0.71 , which is 1.75 times the size of the contemporaneous elasticity from column (1). These numbers are exactly in line with numbers in Becker, Grossman, and Murphy (1991), who in a rational-addiction framework estimate short- and long-term elasticities of -0.40 and -0.75 . We should point out that in our sample, the longterm elasticities generated by price are only slightly larger than the short-term estimates in column (4), again indicating that price and tax are not interchangeable variables.

We can also generate a long-term elasticity from the four experiments listed in Table 4 by comparing the percentage changes in price and quantity in these four states with national trends. Let $Q_{s 0}$ be the consumption in a state in the year prior to a tax change, and let $Q_{\mathrm{s} 3}$ be the consumption three years later. Let $Q_{a 0}$ and $Q_{a 3}$ be corresponding numbers for the U.S. The percentage change in consumption in the state can be approximated by the ratio $\ln \left(Q_{s 3} / Q_{50}\right)$. If we assume that the consumption in this state would have fallen by the national rate had a tax hike not occurred, an estimate of the change in consumption generated by the tax change is then $\% \Delta \mathrm{Q}=\ln \left(\mathrm{Q}_{\mathrm{s} 3} / \mathrm{Q}_{\mathrm{s} 0}\right)-\ln \left(\mathrm{Q}_{\mathrm{a} 3} / \mathrm{Q}_{\mathrm{a} 0}\right)$. If the variable $P$ measures price and we assume prices at the state level would have progressed at the national rate in the absence of a tax hike, then the impact of taxes on price can be estimated as $\% \Delta \mathrm{P}=\ln \left(\mathrm{P}_{\mathrm{s} 3} / \mathrm{P}_{\mathrm{s} 0}\right)-\ln \left(\mathrm{P}_{\mathrm{a} 3} / \mathrm{P}_{\mathrm{a} 0}\right)$. We can then con- 
struct a synthetic estimate of the long-term elasticity of demand from these four experiments by simply constructing the ratio $\% \Delta \mathrm{Q} / \% \Delta \mathrm{P}$. These results are reported in the final columns of Table 4 . Notice that for three states, the long-term elasticity generated from three years of consumption and price data is similar to that constructed from the regression model in Table 3.

These state-specific analyses are not without their problems. First, in some states, the trend break in consumption in treatment states appears before the tax increase. In other states like Massachusetts, tax revenues were used to fund anti-smoking programs, so that the role of taxes may be overstated. However, the results from this exercise do suggest that the adjustment to a higher tax may take a few years, but more importantly, the elasticities generated from marginal tax changes may be used to estimate the effects of non-marginal tax changes.

4.2.2 Estimates from Individual Data In addition to the aggregate state-level analysis in the previous section, we can also generate estimates of the effect of taxes on cigarette consumption by using individuallevel data on smoking. To exploit the variation in tax changes within a state over time requires that we have panels of repeated cross sections that allow us to identify a person's state of residence. To generate estimates for current policy discussions, we also need data with recent samples. The most readily available data source that has all of these qualities is the Behavioral Risk Factor Surveillance System (BRFSS). BRFSS is a stratified sample administered and supported by the Behavioral Surveillance Branch (BSB), National Center for Chronic Disease Prevention and Health Promotion (NCCDPHP), and Centers for Disease Control and Prevention (CDC). The BRFSS consists of yearly state-level data on health and risk behavior collected through random telephone surveys of private households. Only one adult per phone interview is questioned. Calls are made during day and evening hours, seven days a week, within a two-week period every month. The survey questions include a combination of individual-characteristic, health-practices, and risk-behavior questions. The number of participating states has increased from 22 in 1985 to 50 in 1995 . The number of individuals included in the survey has increased from 25,219 in 1985 to 109,192 in 1995.

Some simple descriptive statistics are reported in the first row of Table 5. Pooling data from all years of BRFSS, we generate a sample of 812,185 observations, making this the largest sample ever used to construct cigarette demand estimates for the adult population. In our sample, 24 percent of adults smoke, and smokers on average consume nearly 19 cigarettes per day. 


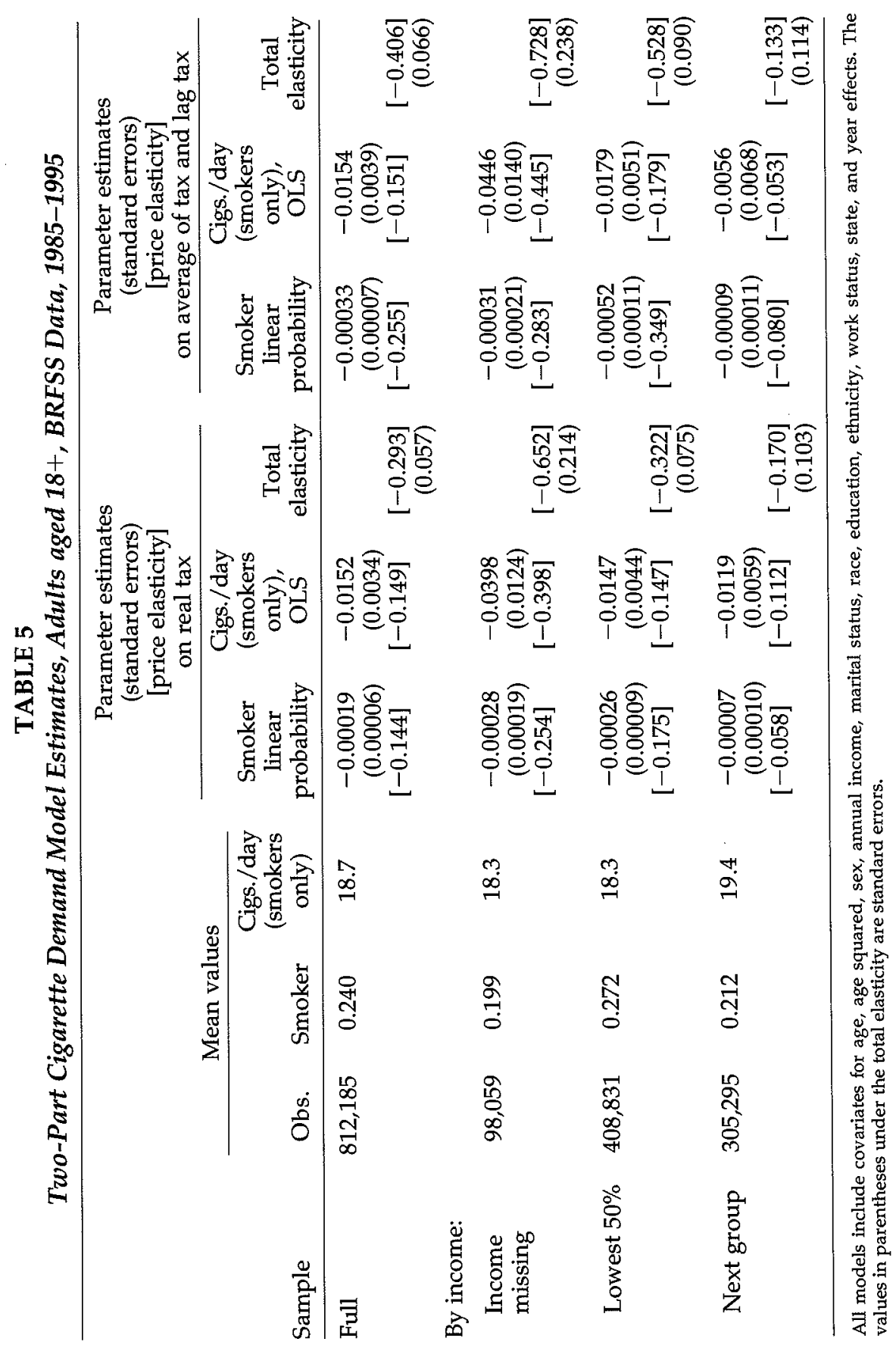


With individual-level data, we employ a "two-part" estimation procedure to model cigarette demand. In the two-part framework, the decision to smoke and the intensity of smoking are modeled separately. The two-part model has been used extensively in the health economics field to model the demand for medical care (Manning et al., 1987), smoking (Lewit and Coate, 1982; Lewit, Coate, and Grossman, 1981; Wasserman, Manning, Newhouse, and Winkler, 1991; Evans and Farrelly, 1998; Evans and Ringel, forthcoming; Evans, Farrelly, and Montgomery, 1998), and drinking (Manning, Blumberg, and Moulton, 1995).

The dependent variable used in the first part of the two-part model is a simple indicator that equals one if the person is a current smoker. Given the discrete nature of the dependent variable, a limited dependentvariable model such as a probit or logit is typically estimated. Due to the extreme number of observations and covariates in our model, we estimate a linear probability model instead. In past cigarette demand models, we have found that results from a linear probability model are surprisingly similar to the probit estimates (Evans and Farrelly, 1998; Evans, Farrelly, and Montgomery, 1998; Evans and Huang, 1998); however, there are exceptions (Evans and Ringel, forthcoming). In this case, linear-probability estimates were very similar to probit ones. In the second stage of the two-part model, we model the demand for cigarettes per day among smokers; the dependent variable is entered linearly, and the model is estimated by OLS. The set of covariates is the same in both equations. We include state and year effects, the real tax in 1997 cents per pack, age, age squared, sex, and categorical variables for annual income, marital status, race, education level, work status, and race/ ethnicity. Sample weights are used in all models.

The results from the two-part model are reported in the first row of Table 5. On the left-hand side of the table, we report results using a contemporaneous measure of price. We also report the coefficient on real tax from the linear probability smoking participation model and the model of daily use among smokers. Both of these coefficients are precisely estimated. We translate the parameter values into price elasticities using a variant of equation (3) above. The sum of the participation and intensity-of-use elasticities is the total elasticity of demand. In the first case, we find a total demand elasticity of -0.29 , with half the elasticity coming from a drop in participation and the other half coming from a reduction in smoking intensity by remaining smokers. This result is consistent with most prior estimates in the literature. Using data from 1976, Lewit and Coate (1982) estimate a total demand elasticity of -0.42 ; using data from 1979, Mullahy (1985) estimates a total demand elasticity of -0.47; Wasserman, Manning, Newhouse, and Winkler (1991) esti- 
mate a value of -0.28 for 1988; and Hu et al. (1995) use data for California from 1985 to 1991 and estimate a total elasticity of -0.46 .

Respondents in the BRFSS are surveyed throughout the year, yet our tax measure is taken at a fixed point in time. For some people, the tax variable may be subject to some measurement error. Smoking is also a dynamic process, and tobacco consumption today may be a function of current as well as recent taxes and prices. To lessen the impact of the timing of the tax measurement on the estimates, we construct an average tax measure using data on current and previous-year taxes. The results using the average tax measure are presented in the right-hand panel of the table. In this model, the participation elasticity rises in value from -0.14 to -0.26 , with no comparable jump in the intensity-of-use elasticity.

In this case, we found some difference between models with price and models with tax. The coefficients (standard errors) on the price variable in the first and second parts are $-0.00026(0.00005)$ and -0.01423 (0.0026) respectively. Unlike the results using aggregate data, the use of price or tax is not critical in this sample. To illustrate the need to use pooled time-series and cross-sectional data in generating the parameter estimates, we produced results using only single cross sections of data for all years in the sample. In these models, we remove the state effects and add a series of regional dummy variables. The implied price elasticities of demand from these models were all over the map, ranging from -7 in 1988 to 8 in 1995, illustrating how results from single cross sections are very sensitive to the time period of analysis.

In general, the results in Table 5 are consistent with the results in Table 3. Our best estimate is that the elasticity of demand in the short run is around -0.30 to -0.50 , with roughly half of any demand change coming from a drop in smoking participation. Long-term elasticities may however be 1.75 times short-term ones.

\subsubsection{Estimates from Other Studies Using Similar Methodology The} results discussed above are quite similar to another recent study that uses individual-level data from multiple years large-scale national surveys. Farrelly et al. (1998) use data from the 1976-1980, 1983, 1985, and 1987-1994 NHIS supplements that contain questions on smoking. ${ }^{13} \mathrm{His}$ model is similar in many respects to ours, since he controls for most of the same covariates, including fixed-state and year effects. The one differ-

13 In the public-release version of the NHIS data, only regions of the country are identified. In order to match taxes to individuals, Farrelly et al. (1998) received state identifiers from the producers of the NHIS, the National Center for Health Statistics. 


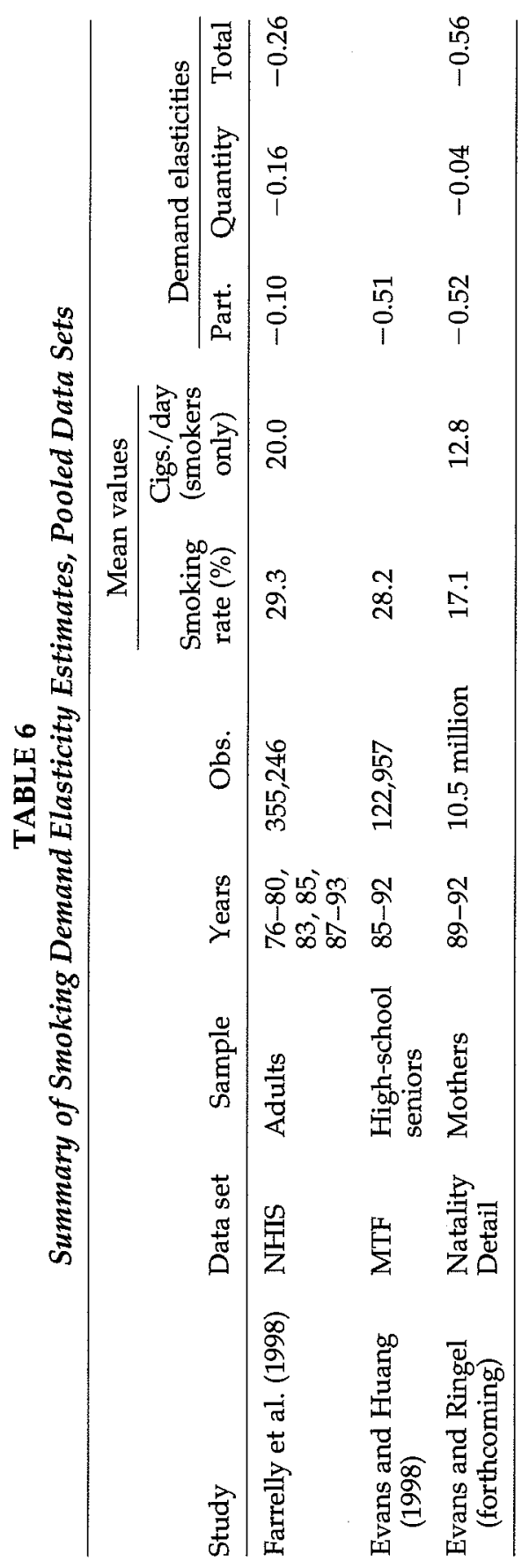


ence between the two models is that Farrelly et al. use price instead of tax as the covariate of interest. A summary of results from their study is given in the first row of Table 6. Their sample includes 355,246 people, 29.3 percent of whom were smokers. The two-part demand elasticities and the total elasticity are very close to the estimates we report in the first half of Table $5 .{ }^{14}$

Although nearly every study using aggregate data or individual-level data for adults finds cigarette consumption is responsive to higher prices and taxes, the evidence on teen smoking is not so clear. Some studies find youths and young adults are much more responsive to cigarette prices than older groups, with overall price elasticities for this group ranging from -1.45 to -0.63 and participation elasticities ranging from -1.20 to -0.588 (Lewit and Coate, 1982; Lewit, Coate, and Grossman, 1981; Grossman, Sindelar, Mullahy, and Anderson, 1993; Chaloupka and Wechsler, 1995; Chaloupka and Grossman, 1996). On the contrary, others find young adults are not responsive to cigarette prices (Wasserman, Manning, Newhouse, and Winkler, 1991; Chaloupka, 1991; DeCicca, Kenkel, and Mathios, 1998).

A set of results consistent with the estimation methodology used above is contained in the work of Evans and Huang (1998). In that paper, the authors use group data provided by the MTFP on smoking rates by age-race-sex-year-state cells for high-school seniors who were part of the 1977-1992 surveys. The sample consists of survey responses for over a quarter of a million high-school seniors, making it the largest data set on the smoking habits of teens ever used for this type of demand analysis. Using data for the 1985-1992 period, Evans and Huang were able to estimate smoking participation demand elasticities, again controlling for state and year effects. The description statistics for their sample are reported in the second row of Table 6 . They estimate a price participation elasticity of about -0.50 , which is twice the size of the largest estimate of the same quantity we calculate for adults using the BRFSS data.

The large elasticity and the real drop in name-brand prices can help explain at least some of the recent increase in smoking among teens. On Marlboro Friday in April of 1993, name-brand prices were reduced by 20 percent overnight. Recall from Figure 1 that real prices have not rebounded from this large drop in nominal prices and teen smoking increased by 8.7 percentage points between 1992 to 1997. Since teens smoke almost exclusively name-brand cigarettes, this drop in price is expected to increase smoking rates by 10 percent $[(-0.2) \times(-0.5)]$. With

14 Although we do not report standard errors on these elasticities, the coefficients on the underlying parameter values are statistically significant. 
a base smoking rate of 27.8 percent in 1992, the drop in name brand cigarettes in 1992 is responsible for about 32 percent of the increase in teen use.

Another paper examining the effect of taxes within a fixed-effects framework is Evans and Ringel's (forthcoming) paper on whether higher cigarette taxes can discourage smoking among pregnant women. This is a particularly interesting group to consider because smoking during pregnancy has been shown to decrease birth weights. Thus, tax-induced smoking cessation should immediately improve birth outcomes. Evans and Ringel use data on maternal smoking during pregnancy from the Natality Detail data. These data are published annually by the National Center for Health Statistics and contain a census of births that occurred in the U.S. They are taken directly from birth records and contain information regarding the newborn (including birth weight), as well as detailed demographic characteristics of the mother. Most of the information is collected at the time of the birth by the health-care provider. In 1989, the number of variables reported in the Natality Detail data was expanded to include information such as the method of delivery, medical procedures used during delivery, and self-reports of smoking and drinking during pregnancy. Using data on maternal smoking for over 10.5 million women who gave birth during 1989-1992, Evans and Ringel find the smoking-participation price elasticity of demand is -0.50 , but little, if any, impact of higher taxes on the intensity of smoking among remaining smokers. The results from this paper are summarized in the last row of Table 6. Evans and Ringel also show that higher taxes translate into better birth outcomes, with average birth weights improving in states that raise excise taxes.

There are two potential problems with all of the estimates we discuss above. First, some authors have noted that the effects of state taxes may be mitigated by cross-border purchases (Baltagi and Levin, 1986; Coats, 1995). We do not believe this should dramatically change the results outlined above. In their work on cigarette taxes and maternal smoking, Evans and Ringel (forthcoming) used data on a pregnant woman's county of residence to identify women who lived within a short distance of a county in another state with a lower tax rate. In a sample of over 7 million, they did not find a statistically significant effect of border taxes. More importantly, the addition of border tax rate had no impact on the own-state tax coefficient. Second, if other state policies related to tobacco are changing at the same time, our excise-tax coefficient may be picking up the effects of those changes in regulations (Wasserman, Manning, Newhouse, and Winkler, 1991; Chaloupka and Grossman, 1996). For example, many states have adopted restrictions on workplace and 
public-area smoking, and a number of studies have demonstrated that workplace policies do reduce smoking participation and intensity by increasing the cost of smoking on the job. ${ }^{15}$ We believe that the available evidence casts doubt on whether these state laws bias the tax effect. These laws will only be a concern if the statutes actually reduce demand. There is little evidence on this point. Most of the studies that have examined how non-tax state policies affect smoking use cross-sectional models which are subject to the criticisms that we outline above. When authors have examined the effect of these other laws on smoking with panels of repeated cross-sections, they have found it lacking. Farrelly and Evans (1998) demonstrate that there is little correlation between state laws governing workplace smoking and actual workplace policies and no effect of these policies on smoking among workers. They suggest that the desire on the part of firms to reduce workplace smoking swamps any effect of the laws in increasing exposure to workplace bans. Similarly, Evans and Ringel (forthcoming) demonstrate that the tax coefficient changes little when they control for numerous types of state laws on public smoking in their basic cigarette demand models.

\section{THE EFFECT OF TAXES ON PUBLIC FINANCES}

Cigarettes are taxed at all levels of government, generating over $\$ 13$ billion in revenues in fiscal year 1997. In this section, we examine some issues concerning the taxation of tobacco. First, we illustrate that because taxes are levied at all levels of government, large increases in tax at one level can greatly diminish revenues to another. Secondly, we examine questions of tax fairness.

\subsection{Federal and State Tobacco Tax Revenues}

Because the elasticity of demand for cigarettes is low, excise-tax hikes are a ready source of revenue for all levels of government. Higher cigarette taxes have been proposed as a revenue source for education, reductions in property taxes, the elimination of the marriage penalty, universal health insurance, and cleanup of Puget Sound.

As a permanent revenue source, excise taxes are an imperfect tax instrument. In general, inflation tends to erode the base of any excise tax. As we demonstrated in Figure 4, although there have been numerous increases in the state and federal excise taxes on cigarettes, their real value has remained constant over the past 30 years. The nominal value of revenues is also subject to the time path of consumption: as aggregate

15 See Evans, Farrelly, and Montgomery (1998) for a review. 
smoking rates decline, so too will the revenues from any particular tax. These two effects can be substantial. For example, aggregate sales of cigarettes fell by 26 percent from 1981 to 1997 while the consumer price index increased by 80 percent. These two limitations of excise taxes are only addressed at the state and federal level by subsequent hikes in the tax rates. In contrast, both the Settlement and the McCain bill had builtin inflation adjustment for the fee schedule. Interestingly, both the Settlement and the later years of the McCain bill also adjusted down fee payments as aggregate consumption declined. These adjustments had the effect of generating certainty in the real per-pack tax change but generating uncertainty in the level of revenues.

Because cigarette taxes are levied by all levels of government, tax hikes by one level of government will, by construction, reduce revenues to another by reducing the level of consumption. Estimates of the aggregate trade-off can be obtained by using the results given above. To make things simple, suppose excise taxes are levied at two levels of government at the tax rates $t_{1}$ and $t_{2}$. Let $q$ be the current consumption of cigarettes in packs per year, and $p$ be the current price. Total tax revenue from all sources is defined as $R=\left(t_{1}+t_{2}\right) q$. If $\partial p / \partial t_{i}=1$ as was demonstrated above, then the revenues gained by a hike in (say) $t_{1}$ can be shown to equal $\partial \mathrm{R} / \partial \mathrm{t}_{1}=\mathrm{q}\left[1+\left(\mathrm{t}_{1}+\mathrm{t}_{2}\right) \epsilon_{\mathrm{d}} / \mathrm{p}\right]$, where $\mathrm{q}\left(1+\mathrm{t}_{1} \epsilon_{\mathrm{d}} / \mathrm{p}\right)$ is the revenue gained by level 1 and $\mathrm{qt}_{2} \epsilon_{\mathrm{d}} / \mathrm{p}$ is revenue lost by level 2 . Using shortand long-term elasticities of -0.4 and -0.7 respectively, and 1997 values for the other parameters $(\mathrm{q}=23.9$ billion packs, $\mathrm{p}=\$ 185.4$, federal and average state tax rates of 24 and 32 cents per pack respectively), we estimate the impact of a 50-cent tax hike on revenues for two levels of government. The results are shown in Table 7 . In the first case, we consider that the whole tax hike is at the federal level, and in the second case, we assume all states increase taxes by the same amount as in the Settlement. Notice that in the short run, a federal tax hike of 50 cents will increase federal revenues by $\$ 11.35$ billion, but almost $\$ 0.8$ billion will be lost due to a reduction in state revenues as aggregate consumption falls by 10.8 percent. In the long run, a 50 -cent federal tax hike will reduce state revenues by almost 20 percent. In the case of a uniform increase in state taxes such as in the Settlement, the fraction of revenues lost by the federal government will also equal 10.8 percent. We should also note that this understates the total lost revenue, since sources such as sales taxes will also be affected.

\subsection{The Regressivity of Cigarette Taxes}

One frequent objection to almost any excise tax is that it is regressive. In his review of the progressivity of different tax regimes, Suits (1977) finds 


\section{TABLE 7}

Tax Revenues Generated by a 50 Cent/Pack Tax Hike, 1997

\begin{tabular}{|c|c|c|c|c|c|}
\hline \multirow[b]{2}{*}{ Level of govt. } & \multirow[b]{2}{*}{$\begin{array}{c}1997 \text { tax } \\
\text { revenues } \\
\text { (\$billions) }\end{array}$} & \multicolumn{2}{|c|}{$\begin{array}{c}\text { Short-term } \\
\text { elasticity }=-0.4\end{array}$} & \multicolumn{2}{|c|}{$\begin{array}{c}\text { Long-term } \\
\text { elasticity }=-0.70\end{array}$} \\
\hline & & $\begin{array}{c}\Delta \text { in } \\
\text { revenues } \\
\text { (\$billions) }\end{array}$ & $\begin{array}{l}\% \Delta \text { in } \\
\text { revenues }\end{array}$ & $\begin{array}{c}\Delta \text { in } \\
\text { revenues } \\
\text { (\$billions) }\end{array}$ & $\begin{array}{l}\% \Delta \text { in } \\
\text { revenues }\end{array}$ \\
\hline \multicolumn{6}{|c|}{ Federal tax hike of $\$ 0.50 / p a c k$} \\
\hline $\begin{array}{l}\text { Federal } \\
\text { States } \\
\text { Total }\end{array}$ & $\begin{array}{r}5.74 \\
7.31 \\
13.05\end{array}$ & $\begin{array}{r}11.35 \\
-0.79 \\
10.56\end{array}$ & $\begin{array}{l}198 \\
10.8 \\
80.9\end{array}$ & $\begin{array}{r}10.88 \\
-1.38 \\
9.50\end{array}$ & $\begin{array}{l}190 \\
18.8 \\
72.8\end{array}$ \\
\hline \multicolumn{6}{|c|}{ All states increase tax by $\$ 0.50 / p a c k$} \\
\hline $\begin{array}{l}\text { Federal } \\
\text { States } \\
\text { Total }\end{array}$ & $\begin{array}{r}5.74 \\
7.31 \\
13.05\end{array}$ & $\begin{array}{r}-0.62 \\
11.18 \\
10.56\end{array}$ & $\begin{array}{c}10.8 \\
153 \\
80.9\end{array}$ & $\begin{array}{r}-1.08 \\
10.59 \\
9.50\end{array}$ & $\begin{array}{c}18.8 \\
145 \\
72.8\end{array}$ \\
\hline
\end{tabular}

The percentages and total dollar values may not be accurately constructed from numbers in the table, due to rounding error.

excise taxes in the U.S. are the most regressive form of taxes. Cigarette taxes are thought to be particularly regressive, since consumption actually falls with increasing income (see Table 1). The relationship between consumption and income has changed over time as smoking rates for individuals with higher family incomes have dropped dramatically. Using data on smoking participation from the 1976-1980, 1983, 1985, and 1987-1994 NHIS, we constructed smoking rates by within-year family income quartiles for those aged 18 and up. ${ }^{16}$ In Figure 6, we graph these rates over time, interpolating values for years when the NHIS did not ask smoking questions. There was very little difference in smoking rates across income groups in 1976. By 1994, smoking rates in the lowest income group had fallen by only 4.6 percentage points, while rates for the highest income group had fallen by about 14 percentage points.

Although smoking rates vary considerably across income groups, there is little variation in daily consumption across income categories.

16 Three caveats should be mentioned. First, the family income question in the NHIS is a categorical variable. In earlier years, there were very few categories, so the fraction of adults in each income group may be the same. Second, our quartile measures are individual-weighted groups of family income. The groups do not represent quartiles of family income, but rather, quartiles of individuals based on reported family income. Third, in each year of the NHIS, roughly 10 to 15 percent of the respondents did not answer the income question, so the income quartiles were constructed from those with reported income. 


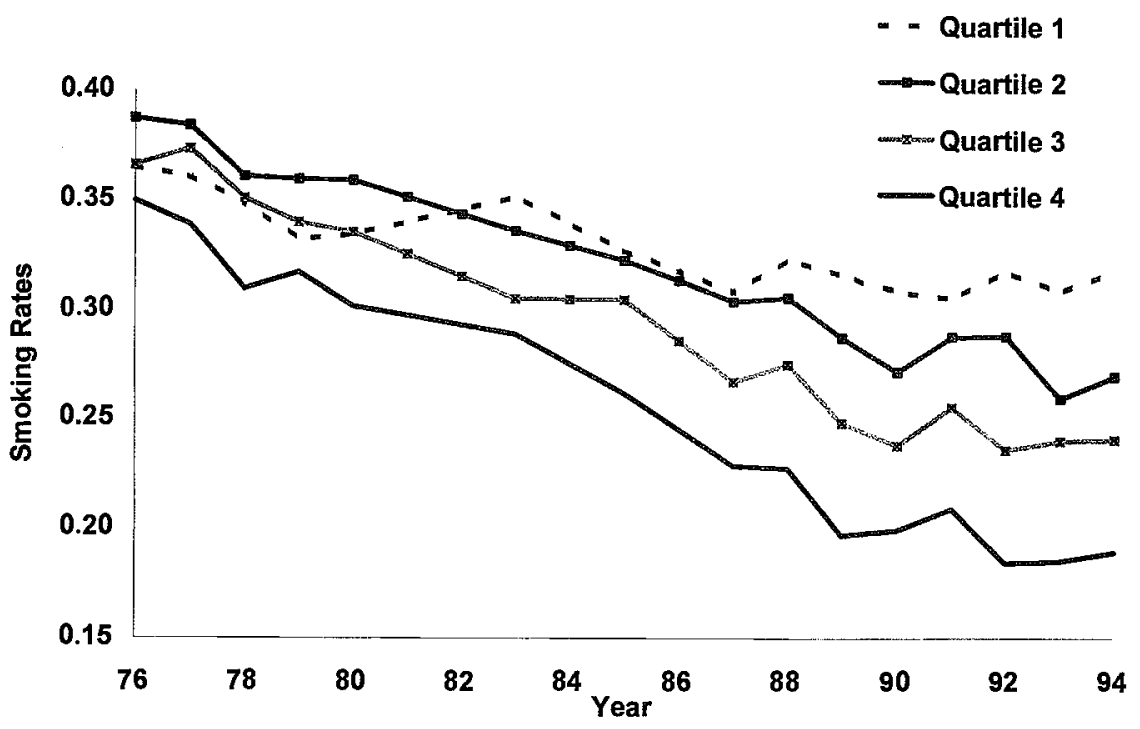

FIGURE 6. Smoking Rates by Family Quartiles-NHIS

Consequently, the fraction of excise-tax dollars paid by each income group can be calculated by simply examining the share of smokers across groups. In 1976, smoking rates for the four income groups (lowest to highest quartiles) were $36.5,38.7,36.6$, and 35.0 percent, respectively. The fractions of excise taxes paid by the income groups are then 24.9, 26.4, 24.9, and 23.8 percent, respectively. In 1994, the smoking rates (percentages of tax paid) of the lowest to highest income quartile groups are 31.8 (31.2), 26.9 (26.5), 24.0 (23.6), and 18.9 (18.6). Cigarette taxes have become more regressive over time. By 1994, cigarette taxes are not just regressive in the proportion of income devoted to pay taxes, but the absolute dollar value paid by low income groups is greater than that paid by higher income groups.

A number of authors have questioned whether the regressivity of a tax at a point in time is an accurate measure of the lifetime burden of the tax (Pechman, 1985; Poterba, 1989, 1991; Lyon and Schwab, 1995). In the case of cigarettes, a life-cycle perspective is expected to alter the lifetime incidence for two reasons. First, smoking rates are highest among younger adults (see Table 1), a group typically with lower income. Comparison of smoking rates across income classes may be comparing people at very different points in their life. Second, as Poterba $(1989,1991)$ notes, there should be less variation in lifetime income than in annual household income. Consequently, if there is sufficient movement of families 


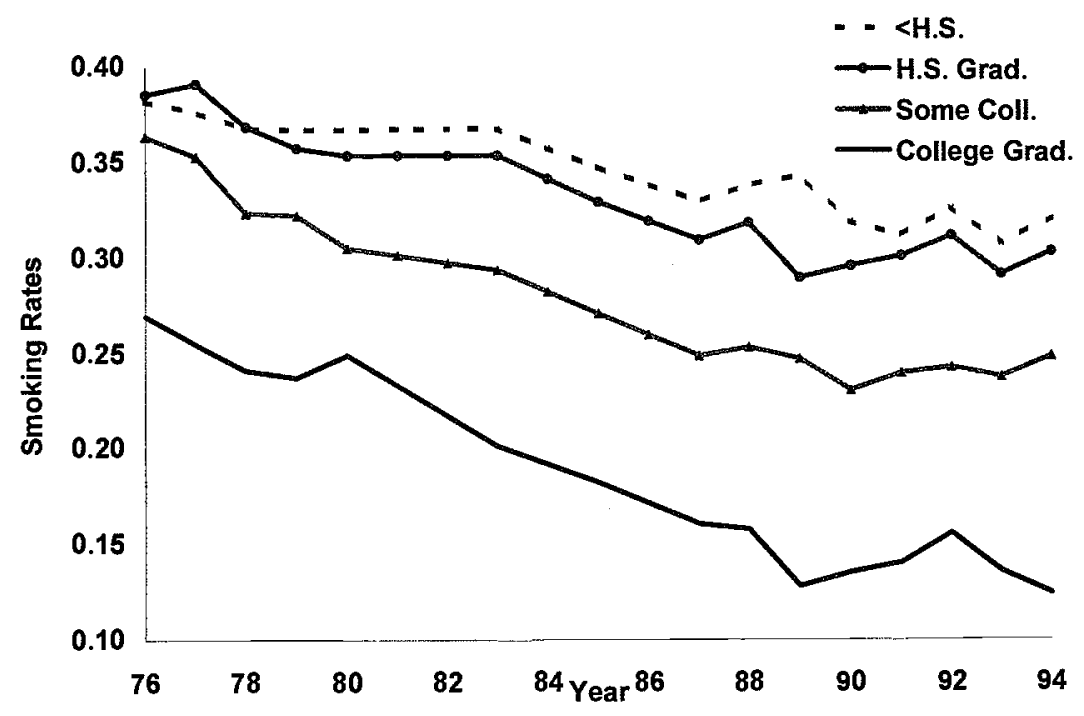

FIGURE 7. Smoking Rates by Education Groups-NHIS

through the income distribution over time, then the lifetime tax burden may be very different from cross-sectional measures.

The evidence would seem to suggest that even in a life-cycle perspective cigarette taxes would still be considered regressive. Part of the rapid decline in smoking for the highest income groups has been generated by a sharp drop in smoking among those with higher levels of education. In Figure 7, we graph the time series in smoking rates for four education groups: (1) less than a high-school degree; (2) a highschool degree, (3) some college, and (4) a college degree. Note that smoking rates for those in the lowest two education groups have fallen by only 7 and 8 percentage points respectively, whereas those in the top two groups have fallen by about 13 percentage points each. Since education is the best single predictor of both smoking and income, it seems unlikely that measuring the regressivity of cigarette excise taxes from a life-cycle perspective will significantly alter the conclusions drawn from cross-sectional measures.

The fact that smoking rates vary considerably across age groups should also not alter the conclusions about regressivity from a cross-sectional analysis. Using data from the TUS to the 1992 and 1993 CPS, we group respondents into 5 -year age intervals $(\leq 24,25-29,30-34, \ldots, \geq 75)$, and for each group we construct group-specific estimates of income quartiles. In Figure 8 , we graph smoking rates for these age-income groups. Notice 


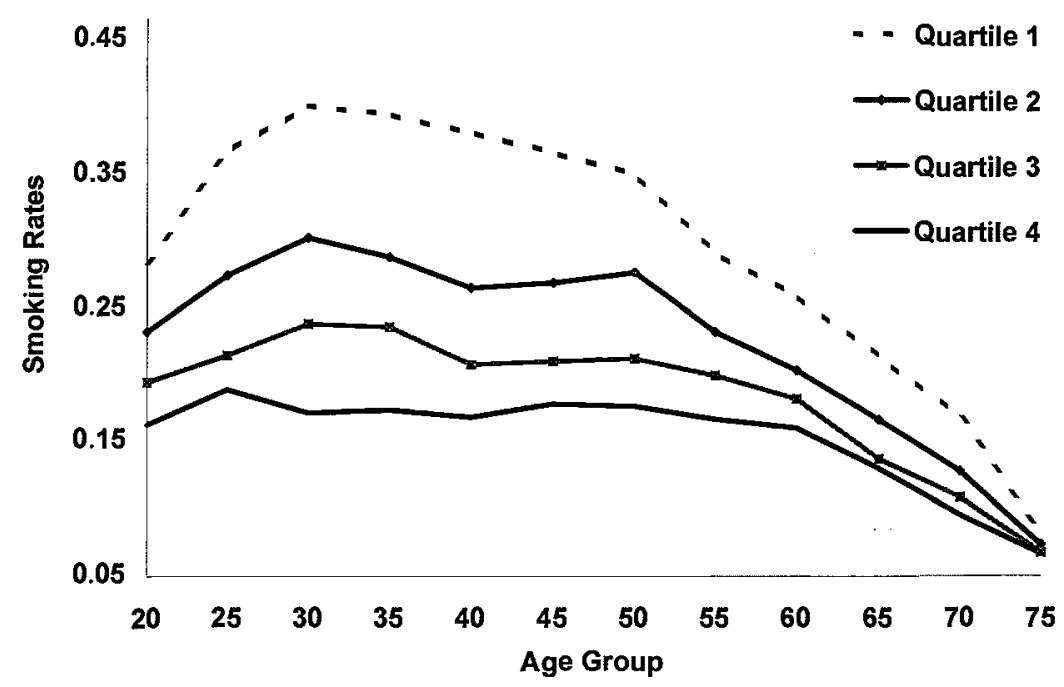

FIGURE 8. Smoking Rates by Income Quartiles and Age-1992-1993 CPS TUS

that for all age groups, smoking rates decline monotonically as family income quartiles rise.

Some of the regressivity of higher cigarette taxes will be mitigated by the fact that higher-income individuals are less responsive to tax changes than others. In the lower half of Table 5, we report demand estimates for three groups: (1) those with missing family income, ${ }^{17}$ (2) those in the lower half with respect to reported family income, and (3) those in the upper half. ${ }^{18}$ The total demand elasticity for the incomemissing group was -0.652 : -0.322 for the lower half and -0.170 for the upper half.

One might question whether we should be concerned about the regressive nature of cigarette excise taxes. Whether the regressivity of tobacco

17 Although those with missing family income have the lowest smoking rates, their demographic characteristics are most similar to those with low incomes. For example, those who do not report family income have fewer years of education and are less likely to be white than those who respond to the income question. Consequently, we view those who do not report income as most likely to be a "low" income group.

18 The BRFSS survey has broad income categories $(<\$ 10,000, \$ 10,000-15,000, \ldots)$. We lumped the broad income categories into three main income groups: group $1(\leq \$ 25,000)$, group 2 ( $\geq \$ 25,000$ ), and group 3 (income missing). In the earlier years of the BRFSS data 50 percent of the observations were within group 1 . This percentage dropped over time. To allow for consistent comparisons by income group, we systematically placed individuals in group 1 to maintain 50 percent within the lowest income group. 
taxes is problematic depends in part on the goal of the tax. If tobacco taxes are levied to raise general revenues, then regressivity is a legitimate concern. However, if cigarette taxes are used to internalize externalities or compensate for inaccurate risk perceptions, then those who smoke the most should pay the most in cigarette taxes. Unfortunately, it is not always clear why some jurisdictions raise cigarette taxes.

\section{THE IMPACT OF COMPREHENSIVE TOBACCO LEGISLATION ON TOBACCO COMPANIES}

As we demonstrated above, higher excise taxes are passed along, dollar for dollar, to consumers in the form of higher prices. The impact on tobacco companies of any tax increase is then greatly diminished as consumers bear the majority of the burden of new taxes. As a result, the ratio of lost profits to revenue raised is quite small. We calculate that for every dollar raised in additional tax revenue, cigarette manufacturers lose only 8 cents in pre-tax profits. ${ }^{19}$

As the FTC (1997) notes, there is also the possibility that firms could benefit from tax increases if they can pass more than 100 percent of the tax hike onto consumers. Given the existing base of smokers and the large gap between price and marginal cost in the cigarette industry, manufacturers only need to raise the price slightly. We calculate that given a $\$ 1$ hike in taxes, cigarette manufacturers need only raise prices by $\$ 1.07$ in order to keep profits at pre-tax levels. ${ }^{20}$

Given the low ratio of lost profits to tax revenues, Bulow and Klemperer (1998) note it is not surprising tobacco firms supported the Settlement. The FTC estimates that by the fifth year, the Settlement would have raised cigarette prices by $\$ 0.62 /$ pack, which, given an elasticity of -0.40 , would

19 Define a firm's profit function as $\pi=p q-\mathrm{C}(q)$, where $\mathrm{C}(\mathrm{q})$ is the cost curve. Roberts and Samuelson (1988) find that production in the cigarette industry can be described by a constant-returns-to-scale technology, so C(q) can be replaced by cq, where $c$ is marginal cost. Treating an excise tax as an increase in marginal costs, an excise tax will not change the value of $p-c$ if firms pass 100 percent of a tax hike onto consumers. Consequently, $\partial \pi / \partial \mathrm{t}$ in this industry can be shown to equal $\mathrm{q}[(\mathrm{p}-\mathrm{c}) / \mathrm{p}] \mathrm{e}_{\mathrm{d}}$. Noting that the change in tax revenues is defined as $q\left(1+(t / p) e_{d}\right)$, the ratio of lost profits to taxes raised is simply $\left|e_{d}(p-c) / p\right| /[1+(t /$ p) $e_{d}$. Bulow and Klemperer (1998) show the marginal before-tax profit per pack of cigarettes is $\$ 0.33$. In 1997, the average tax and price per pack was $\$ 1.85$ and the average tax per pack was $\$ 0.56$. Assuming a short-term elasticity of demand of -0.40 , the numbers indicate that for every dollar raised by higher excise taxes, the cigarette manufacturers lose only 8 cents in pre-tax profits.

20 Using the notation from the previous footnote, when taxes change the price/cost margin, $\partial \pi / \partial t$ can be shown to equal $\mathrm{q}\left[\partial(\mathrm{p}-\mathrm{c}) / \partial \mathrm{t}+\mathrm{e}_{\mathrm{d}}(\mathrm{p}-\mathrm{c}) / \mathrm{p}\right]$, so if $\partial(\mathrm{p}-\mathrm{c}) / \partial \mathrm{t}>-\mathrm{e}_{\mathrm{d}}(\mathrm{p}-\mathrm{c}) /$ $\mathrm{p}$ then $\partial \pi / \partial \mathrm{t}>0$. Using $\mathrm{p}-\mathrm{c}=\$ 0.33, \mathrm{p}=\$ 1.85$, and $\mathrm{e}_{\mathrm{d}}=0.4$, we have $\partial(\mathrm{p}-\mathrm{c}) / \partial \mathrm{t}>0.07$ for $\partial \pi / \partial t>0$. 
raise total revenues by a little over $\$ 13$ billion, costing the cigarette manufacturers $\$ 1.04$ billion in lost profit $(0.08 \times 13)$. Under the Settlement, it would only cost cigarette manufacturers $\$ 1$ billion per year to shed hundreds of billions of dollars of potential liability.

Given the liability protection in the Settlement, it is easy to verify that the Settlement would have been beneficial for the industry. In this section, we use an events study to examine how movements towards and away from settlements altered the value of firms. Modern finance theory suggests a firm's stock market value represents investors' predictions of the firm's present discounted value of future profits. Investors are rational agents and use all available information when making their forecasts. The arrival of new information may alter the investors' predictions and thus the firm's stock market value. ${ }^{21}$ An events study can be structured in a number of ways; we have chosen to follow the methodology outlined in Mullin, Mullin, and Mullin (1995).

We have identified 22 events, starting with the filing of the first state suit against the tobacco industry in Mississippi in May of 1994, that might have led investors to alter their predictions regarding the future profits of the tobacco industry. One difficulty in conducting an events study is determining when information about a particular event was received by investors. For instance, the Settlement was announced on June 20, 1997; however, reports that talks between the industry and the state attorneys general were underway can be found as early as April 16, 1997. Consequently, we will consider several dates for those events for which a single date is not applicable. In most cases, the various dates include the date of the earliest newspaper report that an event will occur and the actual date of occurrence. In the statistical model, each date is considered an individual event. Thus, something like the Settlement will have several events associated with it. A brief description of each event is included in Table 8.

We use daily stock return data to estimate the following model:

$$
R_{\mathrm{it}}=\alpha_{\mathrm{i}}+\beta_{\mathrm{i}} \mathrm{R}_{\mathrm{mt}}+\Sigma_{\mathrm{s}} \gamma_{\mathrm{is}} \mathrm{D}_{\mathrm{ist}}+\epsilon_{\mathrm{it}}
$$

where $R_{\mathrm{it}}$ is the daily return to security $i$ on day $t, \mathrm{R}_{\mathrm{mt}}$ is the return on the $S \& P 500$ Composite Index on day $t, D_{\text {ist }}$ is a dummy variable that is equal to one if event $s$ occurred on day $t$, and $\epsilon_{\mathrm{it}}$ is a random error. This model is estimated for six companies using data from 1993 through June 30,

${ }^{21}$ For examples of events studies in the economics literature see Brown and Warner (1985), Schipper, Thompson, and Weil (1987), Lyon (1989), Mullin, Mullin, and Mullin (1995), and Card and Krueger (1995). 
1998. The companies included in the study are Philip Morris, RJR Nabisco, BAT Industries (the parent company of Brown \& Williamson), Loews (the parent company of Lorillard), U.S. Tobacco, and Brooke Group Ltd. (the parent company of Liggett). While U.S. Tobacco does not produce cigarettes, it does produce chewing tobacco and moist snuff and was named as a defendant in the state suits. Thus, we decided to include it in the study.

The daily stock return data for 1993 through 1997 were obtained from the Center for Research in Security Prices (CRSP). The CRSP data contain a daily return measure adjusted for dividend payments and stock splits. We did not have access to the 1998 CRSP data; therefore, the 1998 data on daily security prices were downloaded from the Dreyfus Brokerage Services, Inc. Web site (http://www.tradepbs.com). To calculate an adjusted daily return measure that would be consistent with the CRSP data, we obtained information from Standard \& Poor's Annual Dividend Record, 1998 on dividend payments and stock splits.

If there is new information provided by an event that leads investors to revise their forecasts of the value of a tobacco firm, it will be reflected in the estimate of the coefficient on the event indicator variable, $\gamma_{\mathrm{is}}$. If the parameter estimate is positive, it indicates the event was beneficial to the firm and increased its stock market value. Since we hypothesize that the Settlement was good for industry, we would expect to find positive estimates of $\gamma_{\text {is }}$ for events that increased the probability of the Settlement.

Since there may be idiosyncratic factors that affect investors' valuation of a particular company, it is useful to average these out by calculating a tobacco-industry response to the different events. The industry response to an event can be measured as the mean value of the estimated coefficients on that event indicator variable across the firms in the industry. In our calculations, the response of Brooke Group Ltd. is excluded from the industry average, since it settled with the attorneys general and would likely respond differently to many of the litigation events.

The results of the events study are summarized in Table 8. The estimates indicate Philip Morris investors are responsive to certain types of new information. Nine of the twenty-one events have a significant impact on Philip Morris daily stock returns. The first announcement that settlement talks were taking place between the industry and the state attorneys general appears to have the largest impact on daily returns, leading to approximately a 10-percentage-point increase. This result indicates investors viewed the Settlement as having a positive impact on the firms' future profits. Interestingly, the actual announcement of the Settlement on June 20, 1997 had a negative impact on daily returns. Until the 


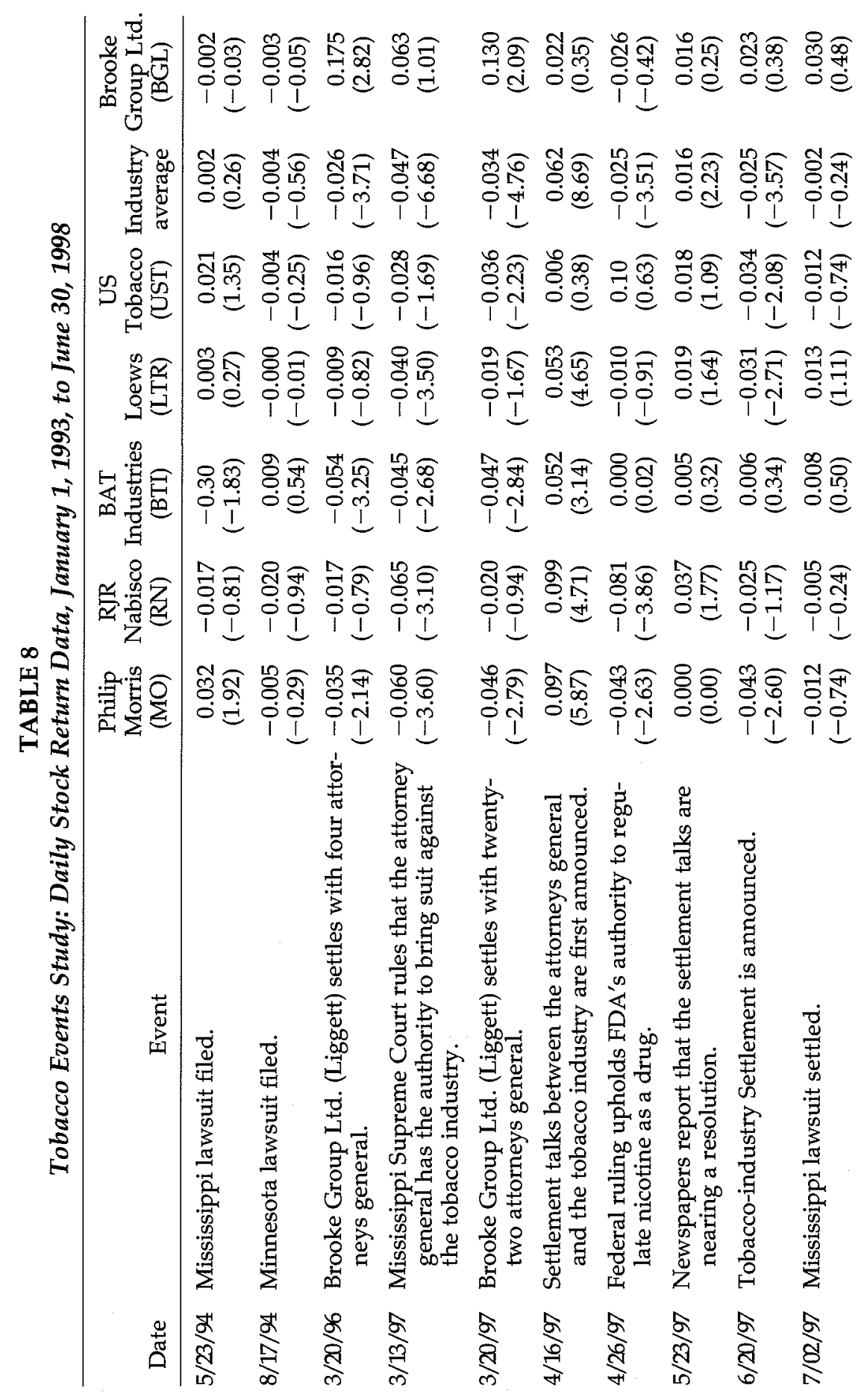




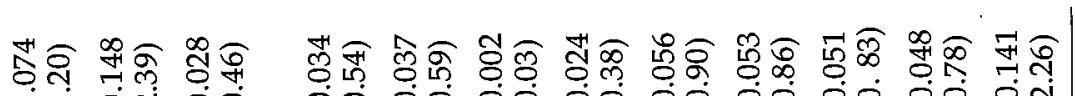

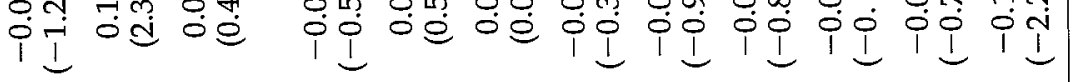

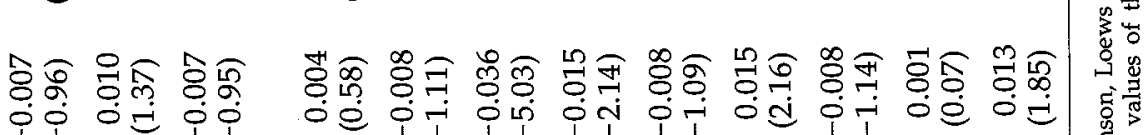

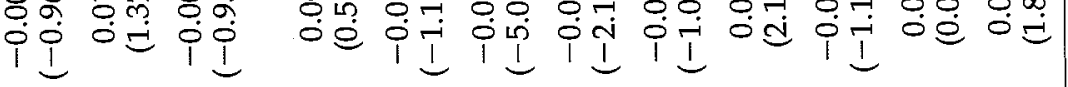

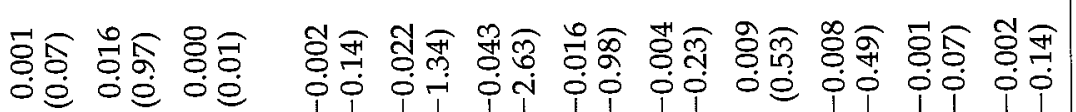
-

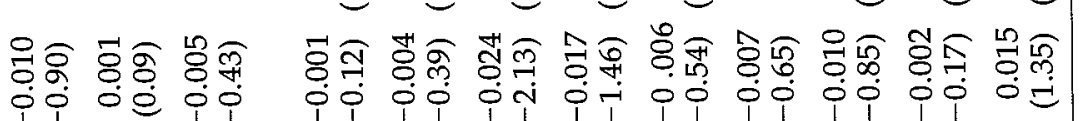

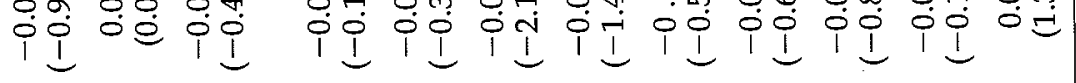

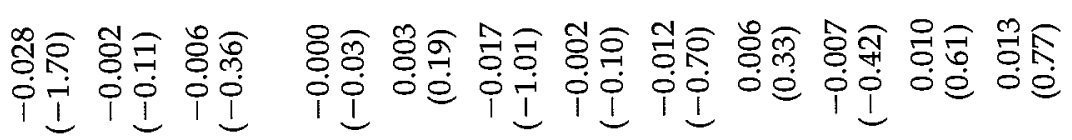

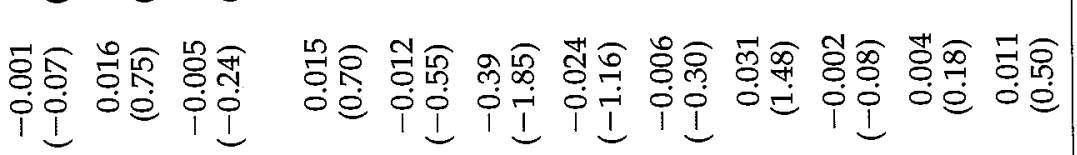

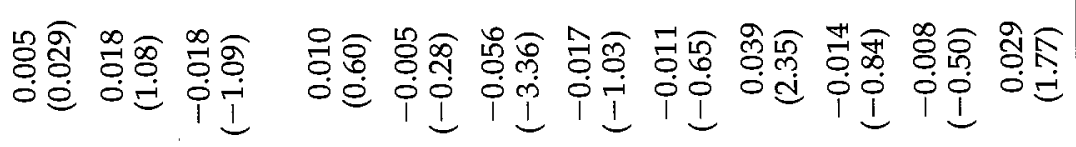

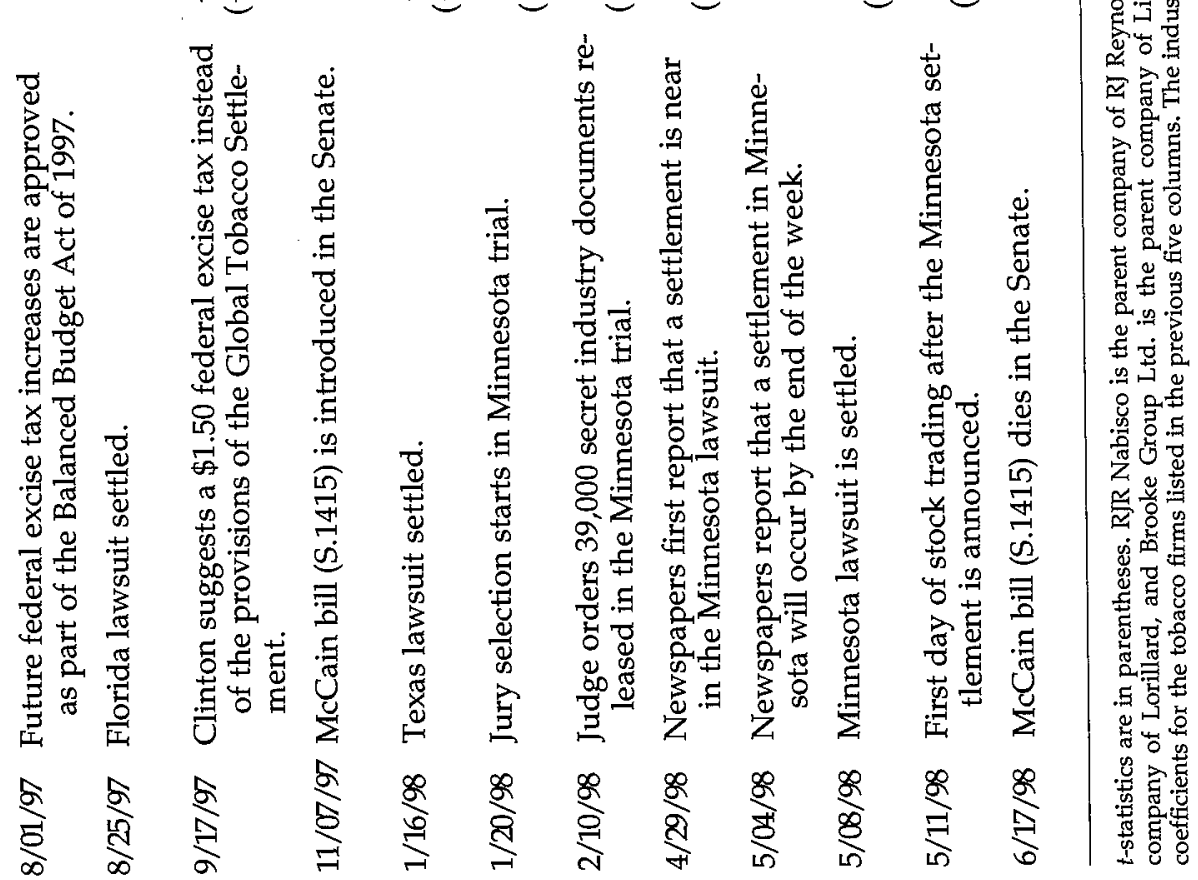


actual announcement was made, investors did not know what its scope and cost would be. The dip in daily returns on June 20,1997 is likely the effect of investors adjusting and revising their forecasts based on the information that the face value of the Settlement approached $\$ 35$ billion.

The estimates for the industry are reported in the sixth column of Table 8. Ten of the twenty-one events are found to have a significant impact on daily returns. Three of these events have a positive impact on investors' forecasts of future profitability. The first announcement that settlement talks were underway between the industry and the states is again the event with the largest effect. The two other positive events for the industry are related to the transfer of new information that settlement talks were nearing a resolution, first in the case of the Settlement and later in the case of the Minnesota trial.

Seven of the ten significant events had a negative impact on daily returns. The event with the largest negative impact came early on in the current wave of tobacco litigation. Though there was little effect on tobacco stocks when Mississippi first brought suit in May of 1994, there was a large impact in March of 1997 when investors saw the case was actually going forward. Similarly, there was a large negative reaction to the start of jury selection in the Minnesota trial in January of 1998. Another event that had a significant negative impact on industry daily returns was when Brooke Group Ltd. settled with twenty-two attorneys general in March of 1997. As part of the settlement agreement, Brooke Group Ltd. agreed to cooperate fully with the attorneys general and to turn over documents that had previously been withheld under attorneyclient privilege. Investors clearly feared Brooke Group Ltd.'s cooperation and the newly released documents would be detrimental to the tobacco industry's case.

The results of this events study support the hypothesis that the Settlement was seen by investors as good for the tobacco industry. Those events which appeared to bring a settlement closer were viewed as positive, while those events which appeared to move the industry and the attorneys general further apart had a negative impact on the firm's stock market value. In contrast, none of the federal initiatives (the McCain bill or President Clinton's tax proposal) registered with the market, indicating that perhaps the investors did not view these proposals as possible from the start.

While the events-study methodology allows us to investigate the impact of specific events, it does not provide a broad picture of what was happening to stock prices in the tobacco industry during this period. To obtain a broad picture, we look at how tobacco company stocks have performed relative to other stocks over the five-year period. To do this, we calculate a 

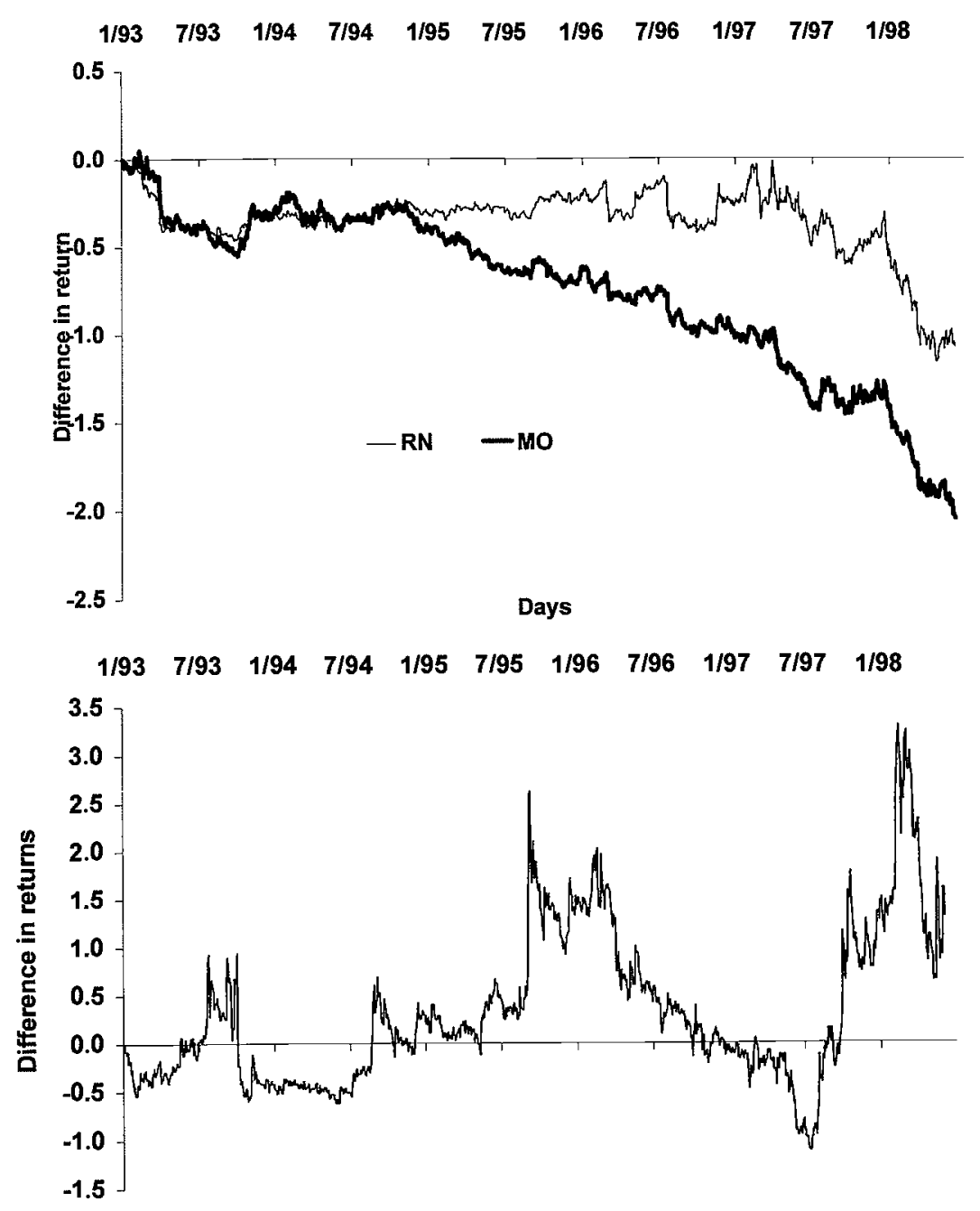

Days

FIGURE 9. Cumulative Returns Relative to SEP 500: (top) Philip Morris and RJR Nabisco; (bottom) Brooke Group Ltd.

cumulative daily return for individual companies from January 1, 1993 and subtract from this the cumulative return for the S\&P 500. In Figure 9a, we graph the cumulative returns for Philip Morris and RJR Nabisco. ${ }^{22}$ Philip

22 Results for other tobacco manufacturers were similar. We focus on these two firms because their sales represent over 70 percent of industry sales. 
Morris has underperformed relative to the S\&P 500 since early in 1993; however, it was not until 1997 that the magnitude of the difference in cumulative returns rose sharply. Although it is not as pronounced, a similar pattern can be seen for RJR Nabisco. Early in 1997 Philip Morris appeared to be rebounding and moving closer to the S\&P 500 in returns. This coincides with the early stages of the Settlement. The first announcement that talks were underway and a settlement was possible was in April of 1997. This upturn for Philip Morris relative to the S\&P 500 supports the hypothesis that the Settlement was viewed as a positive step for the tobacco industry. The dramatic dropoff that took place in the latter part of 1997 and the early part of 1998 might indicate that investors revised their forecasts of future profitability as it became more and more likely that the Settlement would not be implemented, and more restrictive and costly federal legislation might be passed.

The one tobacco company that does not follow the same pattern as Philip Morris and RJR Nabisco is Brooke Group Ltd. (the parent company of Liggett), whose cumulative returns relative to the S\&P 500 are graphed in Figure 9b. In May of 1996, Brooke Group Ltd. settled tobacco lawsuits with four state attorneys general. A year later, it settled with twenty-two more states. As seen in Figure 9b, settling the lawsuits appears to have been quite beneficial. Of the six tobacco companies that we consider, Brooke Group Ltd. is the only one that outperforms the S\&P 500 for any length of time during 1993-1998.

\section{WHY TAX TOBACCO?}

Until now, we have avoided the debate about whether governments should raise the tax on tobacco. Although the answer to this question may seem obvious to some in other academic disciplines, for some economists it is not so clear. One justification for higher cigarette taxes would be if the external costs of smoking exceeded the revenues raised by cigarette taxes. However, three well-publicized studies (Manning et al., 1991; Gravelle and Zimmerman, 1994; and Viscusi, 1995) find smokers "pay their way" and the current level of excise taxes are smaller than the external costs of smoking. Specifically, Manning et al. conclude that in 1986 dollars, the external costs of smoking total $\$ 0.15 /$ pack of cigarettes whereas the states and federal government tax cigarettes an average of $\$ 0.37 /$ pack. An interesting comparison is also noted by Manning et al., who found current levels of alcohol taxes were substantially lower than the external costs generated by alcohol use. The disparities in the results for alcohol and cigarettes are due to two factors. First, there are thousands of external deaths associated with drunk driving and violence, 
that, when monetized using standard estimates of the value of a statistical life, increase the external costs of alcohol use. In contrast, Manning et al. assumed there are no such external deaths associated with cigarette use. The second reason why smokers "pay their way" is the so-called death benefit from smoking-smokers die earlier than nonsmokers, reducing lifetime social security payments (Shoven, Sundberg, and Bunker, 1989) and lifetime health-care costs.

The results from these papers are at the least provocative and at the most call into question whether we should be considering large tax increases at all. However, these studies are not without their critics. Some find it objectionable that death can be considered a "benefit." In more pointed criticism, a number have questioned the authors' definition of external costs. Specifically, Manning et al. define the economic unit as the household, and the effect of smoking on infants and spouses is thus, by assumption, not an external cost. In sensitivity tests, Manning et al. do consider the costs of environmental tobacco smoke (ETS) and the effect of maternal smoking on infants, but in the end, they conclude that even adding these values into their model does not change the basic conclusion that smokers pay their way.

The calculation of the external costs of ETS is clouded by a lack of consensus about the risks associated with passive smoke. Manning et al. only consider as costs an estimated 2,400 lung cancer deaths per year attributed to second-hand smoke. Viscusi (1995) argues that these costs are exaggerated because dose-response curves were based on data generated when tar contents of cigarettes were much higher. However, both studies remark that the vast majority of deaths associated with secondhand smoke are likely exposed spouses. The discussion is complicated further by evidence that ETS could be responsible for between 30,000 and 60,000 heart-disease deaths annually (Glantz and Parmley, 1995), although the science on this issue has been called into question (Steenland, Thun, Lally, and Heath, 1996). The claim that most of the deaths due to ETS are due to in-home exposure is contradicted by the EPA (1992), which found that over 70 percent of the exposure to ETS occurs outside the home. In the end, we do not believe we can add much to this debate. What appears to be lacking is a consensus on the science-how many people are harmed by ETS?

We are however, much more confident that the costs of maternal smoking, ignored in Gravelle and Zimmerman and in Viscusi, are larger than reported in Manning et al. They calculate that including the costs associated with smoking-induced low-weight births increases the external costs of smoking by about $\$ 0.16 /$ pack in 1986 dollars or $\$ 0.22 /$ pack in 1994 dollars. Using a simple accounting exercise, we find the costs associated 
with maternal smoking are in fact quite large. The costs of smoking on infants and children are concentrated in three areas. First, smoking increases the chance a baby will be born with a low birth weight. In 1995, 7.3 percent of newborns in the U.S. had low birth weights (defined as less than 2500 grams). Cigarette smoking has been identified as the "single largest modifiable risk factor for low birth weight . . ." (Shiono and Behrman, 1995, p. 11). The surgeon general (U.S. Department of Health and Human Services, 1989 and 1990) concludes that maternal smoking during pregnancy reduces birth weight by an average of 200 grams and doubles the chance of an infant having a low birth weight. Low-birth-weight infants face a greater risk of developmental and health problems than other infants. Rates of cerebral palsy and other forms of brain injury are higher in low-birth-weight infants, and these risks increase as birth weight declines. By school age, children born with low birth weights are more likely to have learning disabilities, attention disorders, and developmental impairments than normal-weight children (Shiono and Behrman, 1995). Low-birth-weight infants also have higher rates of deafness, blindness, epilepsy, chronic lung disease, and infant mortality (Paneth, 1995). Low-birth-weight infants receive much more medical attention than other newborns. Lewit et al. (1995) calculate that of all medical-care dollars spent during the first year of life, approximately 35 percent are spent on the incremental costs of treating low-birth-weight infants. Much of this cost is due to the longer initial hospital stays for these babies. Since smoking increases the probability of a low birth weight, and these infants generate much higher medical costs than a normal-birth-weight infant, smoking is associated with higher costs of treating newborns (Oester, Delea, and Colditz, 1988; Li, Windsor, and Hassan, 1994). External costs associated with more low birth weights will then take three forms: higher medical expenditures, higher education costs, and infant mortality.

Second, maternal smoking has been shown to significantly increase the risk of sudden infant death syndrome (SIDS). SIDS strikes 4,000 U.S. infants annually, but the rate has fallen considerably over time. Although SIDS was once thought to have no known cofactors, two significant behavior factors have been identified: the sleeping position of the infant and maternal smoking. In a recent paper, DiFranza and Lew (1995) review 12 major case-control studies and conclude that maternal smoking triples the chance children will die of SIDS.

Finally, maternal smoking increases infant mortality and fetal loss. Infant mortality is tied closely to the lower birth weights of children born to smokers. In a review of 13 epidemiological studies, DiFranza and Lew find smoking increases, by about 20 percent, the chance of infant mortality and fetal loss. 
We calculate the costs associated with these factors using a simple accounting procedure. The procedure is similar to the auxiliary analysis conducted by Manning et al. The results from the accounting exercise are reported in Table 9. For this example, we make detailed calculations for 1994. Using standard results from epidemiology, we can easily calculate the fraction of cases for a particular event (e.g., low birth weight) that can be attributed to smoking. Women who do not smoke have a baseline probability of having a low-weight birth, and smoking elevates this probability. The degree to which smoking increases the risk of a lowweight birth is measured by the relative risk ratio, denoted as RR. A relative risk ratio of 2 would mean smoking doubles the chance of a lowweight birth. With the relative risk ratio and the fraction of women who smoke (denoted as $S$ ), we can calculate the fraction of cases in each birthweight category that can be attributed to smoking. In epidemiology, this is typically called the population-attributable risk and is defined as (Kahn and Sempos, 1989; Kelsey, Thompson, and Evans, 1986)

$$
\mathrm{PAR}=\frac{\mathrm{S}(\mathrm{RR}-1)}{1+\mathrm{S}(\mathrm{RR}-1)}
$$

This number times the number of low-weight births will give us an estimate of the cases attributed to smoking.

The cost of treating low-birth-weight infants increases as birth weights decline (Li, Windsor, and Hassan, 1994; Lewit et al., 1995), but maternal smoking increases the chance of a low-weight birth (1500-2499 grams) much more than it increases the chance of a very-low-weight birth $(<1500$ grams $)$. Therefore, we provide separate estimates of how smoking increases the probability a baby is born into each low-birth-weight category and of the costs of treating these children.

In the first two lines of Table 9, we calculate the additional hospitalization costs associated with treating smoking attributable to low-birthweight children. Using data from the 1994 Natality Detail data file, we calculate there were 52,631 babies born weighing less than 2500 grams. Maternal smoking increases the chance of having a baby in this weight category by 49 percent, ${ }^{23}$ and given a smoking rate of 13.9 percent, we

${ }^{23}$ To measure the effect of smoking on the risk of a low-weight birth, we run a logistic regression where the outcome of interest is a binary indicator denoting whether a baby is born with low weight. The covariate of interest equals 1 if the mother smoked during pregnancy. For this analysis, we use the more than 3 million observations from the 1994 Natality Detail with valid responses to the smoking question. We also control for other cofactors that have been shown to be correlated with the incidence of low-weight births, including age, race, Hispanic origin, marital status and education of the mother, parity and 


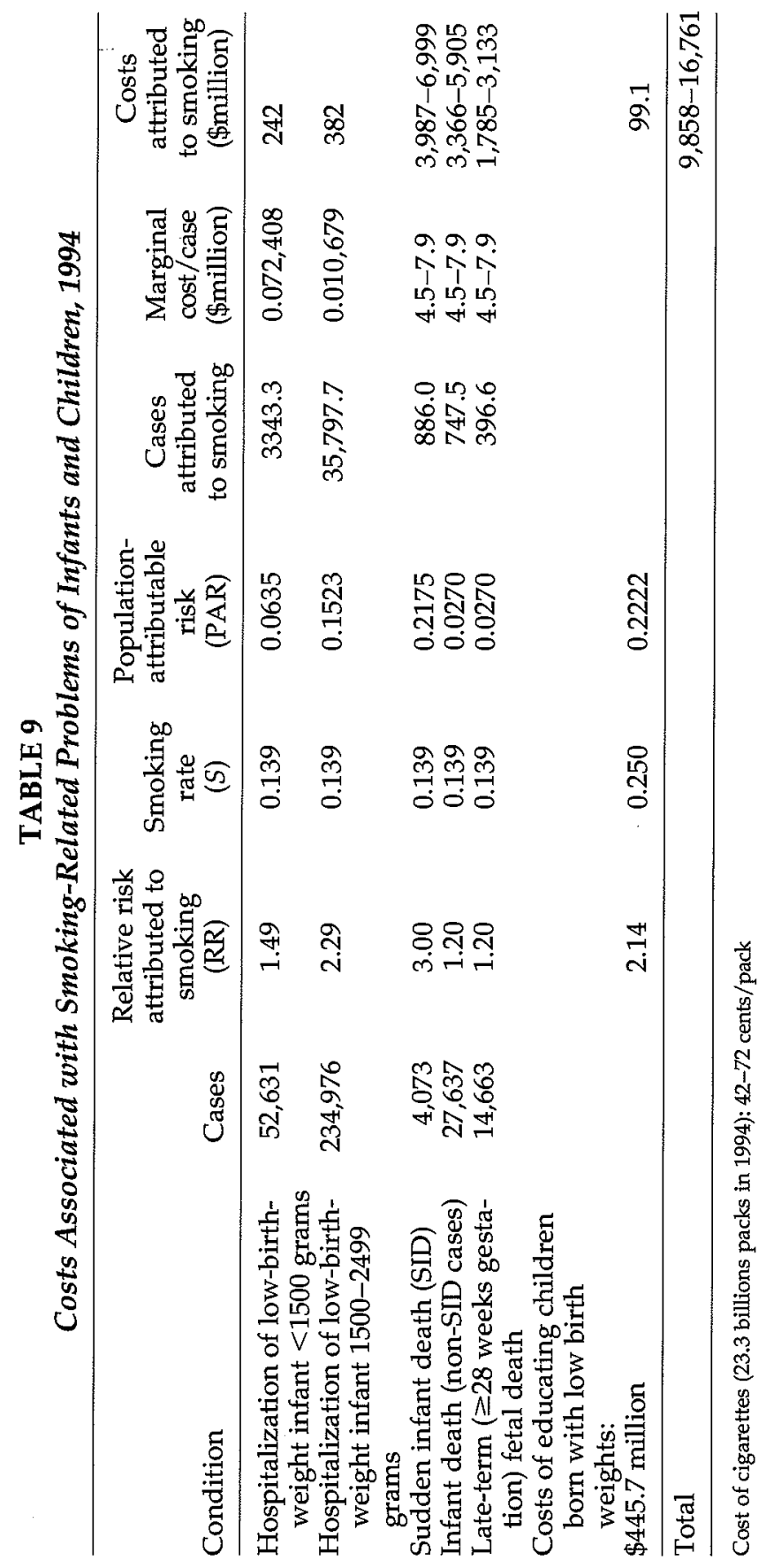


can attribute 6.35 percent of these births to smoking. The marginal cost of treating a child during its initial hospitalization is estimated to be $\$ 72,408$, so we calculate smoking is responsible for an additional $\$ 242$ million in costs for treating very low-weight births. ${ }^{24}$ Using a similar procedure, we calculate there is an additional $\$ 382$ million spent on treating smoking-induced births in the 1500-2499-gram birth-weight category.

In the next line, we report estimates of the cost of educating children enrolled in 1994 who were born weighing less than 2500 grams. Chaikind and Corman (1991) note that during the 1989/90 academic year, the marginal cost of educating children in primary and secondary schools who had low birth weight totaled $\$ 370$ million (in 1990 dollars). Since per-pupil education expenses increase by 20.2 percent from the 19891990 to the 1994-1995 academic year, we inflate Chaikind and Corman's estimates to $\$ 445.7$ million. Since K-12 students in 1994 are aged 5-18, these students were born in the years 1976-1989, when maternal smoking rates were much higher. We use a rough estimate of 25 percent smoking rates for these cohorts and a relative risk factor of 2.14 . We

plurality of the birth, and state of birth. The exponent of this indicator on smoking, called the odds ratio, is roughly equivalent to the relative risk ratio for infrequent events. We estimate two models. First, we define a variable that equals 1 for births $<1500$ grams. The sample mean of the dependent variable is 0.0127 . The logit estimate (standard error) on the smoking variable in this model is $0.397(0.014)$, which translates into an odds ratio of 1.488 . In a second model, we define the dependent variable as 1 if the birth weight is less than 2500 grams. The sample mean of $Y$ in this model is 0.0696 , and the parameter (standard error) on the smoking variable is $0.766(0.006)$, which translates into an odds ratio of 2.145 . We need to convert these numbers into a relative risk for the 1500-2499-gram birth group. The relative risk ratio for the $<2500$-gram group can be thought of as a weighted average of the risks for $<1500$ and for 1500-2499. Using the risks for $<1500$ and for $<2500$ and the fraction of all low-weight births in the $<1500$-gram group, we calculate that the relative risk ratio for the 1500-2499-gram birth-weight group is 2.293 .

24 Data on the cost of treating low-birth-weight infants during their initial hospitalization are taken from Health Care Cost and Utilization Project-3, National Inpatient Sample (NIS) for 1994, http://www.ahcpr.gov.data/94drga.htm. The NIS is a data set that contains all hospital discharge records from a 20-percent sample of U.S. community hospitals from 17 states. The data base reports the number of discharges, the average length of stay, and the average cost per discharge by Diagnosis Related Group (DRG). There are seven DRGs (385-391) associated with newborns. The DRGs for very low, low, and normal birth weight are 386, 387-388, and 389-391 respectively. DRG 385 contains newborns who were transferred or who died in the hospital. Although this group would contain a number of lowbirth-weight infants, we delete them from the analysis. From the hospital discharge data, we use average charges for infants with a DRG code of 386 as the average cost of treating a very low-weight infant (<1500 grams). A weighted average of DRG 387 and 388 is used as the average cost of treating infants weighing between 1500 and 2499 grams. The average cost of treating a normal-weight infant is a weighted average of DRGs 389-391. The marginal costs of treating very low- and low-birth-weight infants are the differences between the cost of treating them and normal-weight infants. 
estimate that 22.22 percent of the costs associated with educating students born with low birth weights can be attributed to smoking.

The largest external costs of smoking are associated with the deaths of infants. There are three classes of deaths we investigate: deaths from SIDS, non-SIDS-related infant mortality, and fetal loss. In each case, we need to monetize the costs of death using value-of-statistical-life estimates. Unfortunately, there is not much literature on the value of life for infants and children. In a detailed review on the value-of-statistical-life estimates generated from labor-market studies, Viscusi (1993) notes that the bulk of the estimates are in the \$4-7-million range, measured in 1990 dollars. We use this range of numbers, inflating the values to 1994 dollars.

Using data from the 1994 U.S. Vital Statistics, we calculate that there were 31,710 infant deaths in the first year of life, of which 4,073 are attributed to SIDS. Using the relative risk factor of 3 from DiFranza and Lew (1995), we calculate a population attributed risk of 21.75 percent, indicating maternal smoking was responsible for 886 SIDS cases in 1994. For non-SIDS deaths, many of the deaths associated with smoking are due to the higher death rates associated with low-weight births. We use a relative risk factor for smoking of 1.20 for non-SIDS deaths (DiFranza and Lew, 1995), indicating smoking is responsible for 748 infant deaths. Although smoking increases the chance of fetal loss at all stages in the pregnancy, it is difficult to know whether all pregnancies, had miscarriage not happened, would have been brought to term. Consequently, we only consider late-term loss (stillbirths during the 28-40 weeks of gestation) as external costs. Data from the U.S. Vital Statistics show there were 14,663 late-term miscarriages, and using the relative risk of 1.2 from DiFranza and Lew, we attribute 397 of these to smoking.

Adding these costs together and using the ranges in the value of life found in Viscusi (1993), we calculate the monetary cost of smokingrelated problems of infants and children in 1994 ranged from $\$ 9.9$ billion to $\$ 16.8$ billion. Dividing this by the 23.3 billion packs of cigarettes sold in fiscal year 1994, we estimate these costs amount to $42-72$ cents/pack. These numbers are much larger than the estimate in Manning et al. (1991), because they use a much smaller value of the life estimate and they do not consider deaths associated with SIDS.

At the other extreme, Hay (1991) estimates the costs associated with maternal smoking are equal to $\$ 4.10 /$ pack in 1990 dollars. Of the more than $\$ 110$ billion in external costs attributed to smoking in this case, Hay estimates that $\$ 87$ billion is due to reduced economic activity of children whose mother's smoked during pregnancy. Hay bases this estimate on a study that finds children whose mothers smoked are four months be- 
hind other children in test scores at age 6 . Hay likens this to a one-third drop in years of education, which, at 6-percent rate of return, means a 2percent drop in economic value. Given the developmental and behavioral problems of many low-birth-weight children, we have no doubt that maternal smoking does reduce future earnings of many children. We question whether one can treat being four months behind in test scores as being equal to losing one-third of a year's education. Thus, we will conclude that our estimates in Table 9 are low, but we make no further calculation.

The results in Manning et al. (1991) and Viscusi (1993) sidestep the difficult issue of whether costs associated with maternal smoking or second-hand smoke should be considered external. In that work, these costs did not change the authors' conclusion that smokers pay their way. Our results, however, make the question more pertinent in that the addition of only the costs associated with maternal smoking are substantial.

\section{CONCLUSION}

Academic work on the economics of tobacco consumption and control has evolved to the point where it can be called an industry. Chaloupka and Warner in their 1998 working paper "The Economics of Smoking" give 23 single-spaced pages of references, mostly written by economists. This research has been featured prominently in debates concerning the likely effects of major tobacco control policies. Some of the interest in this general area of research has diminished in recent months, as both the Settlement and the McCain bill died in Congress. The drop in interest will however be short-lived, because we have probably not seen the last of proposals for major hikes in cigarette taxes. At the time of this writing, representatives from eight states and three tobacco companies are discussing a limited version of the Settlement that would eventually raise cigarette prices by about 30 cents per pack. In recent years, large state tax hikes have raised the tax to $\$ 1.00 /$ pack in Alaska and Hawaii, $\$ 0.825 /$ pack in Washington, and $\$ 0.75 /$ pack in Michigan. In Maryland, a number of candidates for state office have made a state tax hike of $\$ 1.50 /$ pack part of their campaign platform. Subsequently, we should have new rounds of debates about the likely impacts of higher cigarette excise taxes.

\section{REFERENCES}

Baltagi, Bati H., and Dan Levin (1986). "Estimating Dynamic Demand for Cigarettes Using Panel Data: The Effects of Bootlegging, Taxation and Advertising Reconsidered." Review of Economic and Statistics 68:148-155. 
Barnett, Paul G., Theodore E. Keeler, and Teh Hu (1995). "Oligopoly Structure and the Incidence of Cigarette Excise Taxes." Journal of Public Economics $57: 457-470$.

Becker, Gary S., Michael Grossman, and Kevin M. Murphy (1991). "Rational Addiction and the Effect of Price on Consumption." American Economic Review 81:237-241.

- and Kevin M. Murphy (1988). "A Theory of Rational Addiction." Journal of Political Economy 96:675-700.

Brown, Stephen, and Jerold Warner (1985). "Using Daily Stock Returns: The Case of Event Studies." Journal of Financial Economics 14(Summer):3-31.

Bulow, Jeremy, and Paul Klemperer (1998). "The Tobacco Deal." Forthcoming in Brookings Papers on Economic Activity.

Card, David, and Alan B. Krueger (1995). Myth and Measurement: The New Economics of the Minimum Wage. Princeton, NJ: Princeton University Press.

Centers for Disease Control (1992). "Comparison of the Cigarette Brand Preferences of Adult and Teenaged Smokers-United States, 1989, and 10 U.S. Communities, 1988 and 1990." Morbidity and Mortality Weekly Reporter 41:169173, 179-181.

Chaikind, Stephen, and Hope Corman (1991). "The Impact of Low Birth Weight on Special Education Cases." Joumal of Health Economics 10(October):291-311.

Chaloupka, Frank (1991). "Rational Addictive Behavior and Cigarette Smoking." Journal of Political Economy 99:722-742.

- and Michael Grossman (1996). "Price, Tobacco Control and Youth Smoking." NBER Working Paper no. 5740.

, and Kenneth Warner (1998). "The Economics of Smoking." University of Illinois, Chicago. Working paper (forthcoming).

- and Henry Wechsler (1995). "Price, Tobacco Control Policies and Smoking among Young Adults." NBER Working Paper no. 5012.

Coats, R. Morris, (1995). "A Note on Estimating Cross-Border Effects of State Cigarette Taxes." National Tax Joumal 48, 573-584.

Congressional Budget Office (1998). "The Proposed Tobacco Settlement: Issues from a Federal Perspective." Washington, DC: Congressional Budget Office.

Cook, Philip, and George Tauchen (1982). "The Effect of Liquor Taxes on Heavy Drinking." Bell Journal of Economics 13(Autumn):379-390.

DeCicca, Philip, David Kenkel, and Alan Mathios (1998). "Putting Out the Fires: Will Higher Taxes Reduce Youth Smoking?" Presented at the Annual Meetings of the American Economic Association.

DiFranza, Joseph R., and Robert A. Lew (1995). "Effects of Maternal Cigarette Smoking on Pregnancy Complications and Sudden Infant Death Syndrome." Journal of Family Practice 40:385-394.

Environmental Protection Agency (1992). Respiratory Health Effects of Passive Smoking: Lung Cancer and Other Disorders. Environmental Protection Agency, Office of Research and Development, Office of Air and Radiation.

Evans, William N., and Matthew C. Farrelly (1998). "The Compensating Behavior of Smokers: Taxes, Tar, and Nicotine." RAND Journal of Economics 29 (Autumn):578-595.

- Matthew C. Farrelly, and Edward Montgomery (1998). "Do Workplace Smoking Bans Reduce Smoking." Department of Economics, University of Maryland. Working Paper.

_ 
ing: Evidence from Panels of Repeated Cross-Sections." Department of Economics, University of Maryland. Working Paper.

- and Jeanne Ringel (1998). "Can Higher Cigarette Taxes Improve Birth Outcomes?" Forthcoming in Journal of Public Economics.

Farrelly, Matthew C., and William N. Evans (1998)."State Clean Indoor Air Laws and Smoking Participation among Workers." Research Triangle Institute. Working Paper.

Farrelly, Matthew C., et al. (1998). "Cigarette Price Elasticities by Race, Age, Income and Gender." Research Triangle Institute. Working Paper.

Federal Trade Commission (1997). "Competition and the Financial Impact of the Proposed Tobacco Industry Settlement." Federal Trade Commission (September).

Glantz, S.A. and W.W. Parmley (1995). "Passive Smoking and Heart Disease Mechanisms and Risk." Journal of the American Medical Association 73(no. 13): 1047-1053.

Gravelle, Jane, and Dennis Zimmerman (1994). Cigarette Taxes to Fund Health Care Reform: An Economic Analysis. Washington, DC: Congressional Research Service, The Library of Congress. CRS Publication No. 94-214E.

Grossman, Michael, Jody L. Sindelar, John Mullahy, and R. Anderson (1993). "Alcohol and Cigarette Taxes." Joumal of Economic Perspectives 7:211-222.

, Gary Becker, and Kevin Murphy (1994). "An Empirical Analysis of Cigarette Addiction." American Economic Review 84(June):396-418.

Harris, Jeffrey (1987). "The 1983 Increase in the Federal Cigarette Excise Tax." In Tax Policy and the Economy, vol. 1, L. H. Summers (ed.). Cambridge, MA: MIT Press.

- (1994). "A Working Model for Predicting the Consumption and Revenue Impacts of Large Increases in the U.S. Federal Cigarette Excise Tax." NBER Working Paper no. 4803.

Hay, J. (1991). "The Harm They Do to Others: A Primer on the External Costs of Drug Abuse." In Searching for Alternatives: Drug Control Policy in the United States, M.B. Krauss and E.P. Lazear (eds.). Stanford, CA: Hoover Institution Press.

Hu, Te Hi, et al. (1995). "The Demand for Cigarettes in California and Behavioral Risk Factors." Health Economics 4:7-14.

Kahn, Harold A., and Christopher Sempos (1989). Statistical Methods in Epidemiology. New York: Oxford University Press.

Keeler, Theodore, The Wei Hu, Paul Barrett, Willard Manning, and Hai-Yen Sung (1996). "Do Cigarette Producers Price-Discriminate by State? An Empirical Analysis of Local Cigarette Pricing and Taxation." Journal of Health Economics 15:499-512.

Kelsey, Jennifer L., W. Douglas Thompson, and Alfred S. Evans (1986). Methods in Observational Epidemiology. New York: Oxford University Press.

Lewit, Eugene, et al. (1995). "The Direct Costs of Low Birth Weight." The Future of Children 5:35-51.

-, and Douglas Coate (1982). "The Potential for Using Excise Taxes to Reduce Smoking." Journal of Health Economics 1:121-145.

- Douglas Coate, and Michael Grossman (1981). "The Effects of Government Regulations on Teenage Smoking." Journal of Law and Economics 24: 545-569.

Li, Chang Qing, Richard A. Windsor, and Mahmud Hassan (1994). "Cost Differ- 
ences between Low Birth Weight Attributable to Smoking and Low Birth Weight for All Causes." Preventive Medicine 23:28-34.

Lyon, Andrew (1989). "The Effect of the Investment Tax Credit on the Value of the Firm." Journal of Public Economics 38:227-247.

and Robert Schwab (1995). "Consumption Taxes in a Life Cycle Framework: Are Sin Taxes Regressive?" Review of Economics and Statistics 77(August): 389-406.

Manning, Willard, Linda Blumberg, and Lawrence Moulton (1995). "The Demand for Alcohol: Differential Response to Price." Journal of Health Economics 14:123-148.

- Emmett B. Keeler, Joseph P. Newhouse, Elizabeth M. Sloss, and Jeffrey Wasserman (1991). The Costs of Poor Health Habits. Cambridge, MA: Harvard University Press.

_ _ Joseph P. Newhouse, Naihua Duan, Emmett B. Keeler, Arleen Leibowitz, and M.S. Marquis (1987). "Health Insurance and the Demand for Medical Care: Evidence from a Randomized Experiment." American Economic Review 77:251-277.

Mullahy, John (1985). "Cigarette Smoking, Habits, Health Concerns, and Heterogenous Unobservables in a Micro-economic Analysis of Consumer Demand." Charlottesville, VA: University of Virginia. Dissertation.

Mullin, George, Joseph Mullin, and Wallace Mullin (1995). "The Competitive Effects of Mergers: Stock Market Evidence from the U.S. Steel Dissolution Suit." RAND Journal of Economics 26(Summer):314-330.

Oester, Gerry, Thomas E. Delea, and Graham A. Colditz (1988). "Maternal Smoking during Pregnancy and Expenditures on Neonatal Health Care." American Joumal of Preventive Medicine 4:216-219.

Paneth, Nigel S. (1995). "The Problem of Low Birth Weight." The Future of Children 5:19-34.

Pechman, Joseph (1985). Who Paid the Taxes: 1966-1985. Washington, DC: Brookings Institution.

Poterba, James (1989). "Lifetime Incidence and the Distributional Burden of Excise Taxes." American Economic Review 79:325-330.

- (1991). "Is The Gasoline Tax Regressive?" In Tax Policy and the Economy, vol. 5, David Bradford (ed.). Cambridge, MA: MIT Press.

Roberts, Mark J., and Larry Samuelson (1988). "An Empirical Analysis of Dynamic, Nonprice Competition in an Oligopolistic Industry." RAND Journal of Economics 19:200-220.

Schipper, Katherine, Rex Thompson, and Roman Weil (1987). "Disentangling Interrelated Effects of Regulatory Changes on Shareholders Wealth: The Case of Motor Carrier Deregulation." Journal of Law and Economics 30(April):67-100.

Shiono, P. H., and R. Behrman (1995). "Low Birth Weight: Analysis and Recommendations." The Future of Children 5:4-18.

Shoven, John, Jeffrey O. Sundberg, and John P. Bunker (1989). "The Social Security Cost of Smoking." In The Economics of Aging, David Wise (ed.). National Bureau of Economic Research Project Report Services. Chicago and London: University of Chicago Press.

Steenland, K., M. Thun, C. Lally, and C. Heath, Jr. (1996). "Environmental Tobacco Smoke and Coronary Heart Disease in the American Cancer Society CPS-II Cohort." Circulation 94(no. 4):622-628.

Stern, Nicholas (1987). "The Effects of Taxation, Price Control, and Government 
Contracts in Oligopoly and Monopolistic Competition." Journal of Public Economics 32:133-158.

Suits, Daniel (1977). "Measurement of Tax Progressivity." American Economic Review 67(September):747-752.

Sullivan, Daniel (1985). "Testing Hypotheses about Firm Behavior in the Cigarette Industry." Journal of Political Economy 93:586-598.

Sumner, Daniel (1981). "Measurement of Monopoly Behavior: An Application to the Cigarette Industry." Journal of Political Economy 89:1010-1019.

Tobacco Institute (1998). The Tax Burden on Tobacco: Historical Compilation, 1997. Washington, DC: Tobacco Institute.

U.S. Department of Health and Human Services (1989). Reducing the Health Consequences of Smoking: 25 Years of Progress. Rockville, MD: U.S. Department of Health and Human Services, Public Health Service, Centers for Disease Control, Center for Chronic Disease Prevention and Health Promotion, Office on Smoking and Health.

U.S. Department of Health and Human Services (1990). The Health Benefits of Smoking Cessation: A Report of the Surgeon General. Rockville, MD: U.S. Department of Health and Human Services, Public Health Service, Centers for Disease Control, Office on Smoking and Health, DHHS publication no. (CDC) $90-8416$.

U.S. Department of Agriculture, Economic Research Service. U.S. Tobacco Statistics. Downloaded from Web site maintained at Cornell University, http://usda. mannlib.cornell.edu.

Viscusi, W. Kip (1992). Smoking: Making the Risky Decision. New York: Oxford University Press.

- (1993). "The Value of Risks to Life and Health." Journal of Economic Literature 31:1912-1946.

(1995). "Cigarette Taxation and the Social Consequences of Smoking." In Tax Policy and the Economy, vol. 9, James Poterba (ed.). Cambridge, MA: MIT Press.

Wasserman, Jeffrey, Willard G. Manning, Joseph P. Newhouse, and John D. Winkler (1991). "The Effects of Excise Taxes and Regulations on Cigarette Smoking." Journal of Health Economics 10:43-64. 
